JMB

\title{
Identification of a Penta- and Hexapeptide of Islet Amyloid Polypeptide (IAPP) with Amyloidogenic and Cytotoxic Properties
}

\author{
Konstantinos Tenidis ${ }^{1}$, Michaela Waldner ${ }^{1}$, Jürgen Bernhagen ${ }^{2}$ \\ Wolfgang Fischle ${ }^{3}$, Michael Bergmann', Marco Weber ${ }^{1,2}$ \\ Marie-Luise Merkle ${ }^{2}$, Wolfgang Voelter ${ }^{1}$, Herwig Brunner ${ }^{2}$ \\ and Aphrodite Kapurniotu ${ }^{1 *}$
}

\author{
${ }^{1}$ Physiological-chemical \\ Institute, University of \\ Tübingen, D-72076 Tübingen \\ Germany \\ ${ }^{2}$ Laboratory of Biochemistry \\ Chair for Interfacial \\ Engineering, University of \\ Stuttgart, Fraunhofer Institute \\ FhIGB, D-70569 Stuttgart \\ Germany \\ ${ }^{3}$ Gladstone Institute of Virology \\ and Immunology, University of \\ California, San Francisco, CA \\ 94141-9100, USA
}

Pancreatic amyloid is found in more than $95 \%$ of type II diabetes patients. Pancreatic amyloid is formed by the aggregation of islet amyloid polypeptide (hIAPP or amylin), which is a 37-residue peptide. Because pancreatic amyloid is cytotoxic, it is believed that its formation is directly associated with the development of the disease. We recently showed that hIAPP amyloid formation follows the nucleation-dependent polymerization mechanism and proceeds via a conformational transition of soluble hIAPP into aggregated $\beta$-sheets. Here, we report that the penta- and hexapeptide sequences, hIAPP(23-27) (FGAIL) and hIAPP(2227) (NFGAIL) of hIAPP are sufficient for the formation of $\beta$-sheet-containing amyloid fibrils. Although these two peptides differ by only one amino acid residue, they aggregate into completely different fibrillar assemblies. hIAPP(23-27) (FGAIL) fibrils self-assemble laterally into unusually broad ribbons, whereas hIAPP(22-27) (NFGAIL) fibrils coil around each other in a typical amyloid fibril morphology. hIAPP(20-27) (SNNFGAIL) also aggregates into $\beta$-sheet-containing fibrils, whereas no amyloidogenicity is found for hIAPP(24-27) (GAIL), indicating that hIAPP(23-27) (FGAIL) is the shortest fibrillogenic sequence of hIAPP. Insoluble amyloid formation by the partial hIAPP sequences followed kinetics that were consistent with a nucleation-dependent polymerization mechanism. hIAPP(22-27) (NFGAIL), hIAPP(20-27) (SNNFGAIL), and also the known fibrillogenic sequence, hIAPP(20-29) (SNNFGAILSS) exhibited significantly lower kinetic and thermodynamic solubilities than the pentapeptide hIAPP(23-27) (FGAIL). Fibrils formed by all short peptide sequences and also by hIAPP(20-29) were cytotoxic towards the pancreatic cell line RIN5fm, whereas no cytotoxicity was observed for the soluble form of the peptides, a notion that is consistent with hIAPP cytotoxicity. Our results suggest that a penta- and hexapeptide sequence of an appropriate amino acid composition can be sufficient for $\beta$-sheet and amyloid fibril formation and cytotoxicity and may assist in the rational design of inhibitors of pancreatic amyloid formation or other amyloidosis-related diseases.

(C) 2000 Academic Press

Keywords: islet amyloid polypeptide; amyloid fibrils; nucleation; $\beta$-sheet; cytotoxicity

Abbreviations used: $\mathrm{A} \beta, \beta$-amyloid peptide; $\mathrm{AD}$, Alzheimer's disease; ACN, acetonitrile; AFM, atomic force microscopy; CR, congo red; DMSO, dimethyl sulfoxide; EM, electron microscopy; FAB-MS, fast-atom bombardment mass spectroscopy; Fmoc, 9-fluorenylmethoxycarbonyl; FT-IR, Fourier transform infrared spectroscopy; hIAPP, human islet amyloid polypeptide; IAPP, islet amyloid polypeptide; LD-MS, laser desorption mass spectroscopy; MTT, 3-[4,5-dimethylthiazol-2-yl]-2,5-diphenyltetrazolium bromide; rlAPP, rat islet amyloid polypeptide; RP-HPLC, reversephase high-pressure liquid chromatography; $\mathrm{R}^{2}$-SSNMR, rotational resonance solid-state NMR; TBTU, 2-(1Hbenzotriazole-1-yl)-1,1,3,3-tetramethyluronium tetrafluoroborate; tBu, tert-butyl; TFA, trifluoracetic acid; Trt, trityl.

E-mail address of the corresponding author: afroditi.kapurniotu@uni-tuebingen.de 


\section{Introduction}

Amyloid formation is the pathological hallmark of a number of diseases including Alzheimer's disease $(\mathrm{AD})$, the prion protein-related encephalopathies and type II diabetes (Cooper et al., 1987; Lansbury, 1996; Sipe, 1994). Although amyloid fibrils originate from different proteins, they share similar physicochemical properties including morphology and insolubility (Lansbury, 1992; Sipe, 1994). At the level of secondary structure, amyloid from different polypeptides consists of peptide chains in a predominant $\beta$-sheet conformation (Ashburn et al., 1992; Ashburn \& Lansbury, 1993; Gasset et al., 1992; Glenner et al., 1988; Hilbich et al., 1991; Inouye et al., 1993; Jarrett et al., 1993; Lansbury, 1992).

Pancreatic amyloid in humans forms through the aggregation of islet amyloid polypeptide (hIAPP), which is a 37-amino acid residue polypeptide (Scheme 1) (Clark et al., 1987; Cooper et al., 1987; Rink et al., 1993; Westermark et al., 1987). hIAPP-derived amyloid is found in more than $95 \%$ of type II diabetes patients and is believed to be directly related to $\beta$-cell dysfunction and the pathogenesis of the disease (Clark et al., 1987; de Koning et al., 1993; Luskey, 1992). hIAPP in its soluble form is thought to play a role in glucose homeostasis, possibly as an insulin counter-regulatory hormone (Edwards \& Morley, 1992; Rink et al., 1993). However, fibrillar aggregates of hIAPP have been found to be strongly toxic on pancreatic $\beta$-cells (Lorenzo et al., 1994).

Although the sequence of IAPP is strongly conserved over a number of animal species, IAPPderived amyloid is only formed by humans, cats, and some non-human primates (Westermark et al., 1990). Rodents do not form pancreatic amyloid, although there are only six amino acid residues by which the rat sequence (rIAPP) differs from its human (hIAPP) analog (Westermark et al., 1990). Five of these six amino acid residues are located in the region between residues 20 and 29 (Scheme 1). Therefore, the amyloidogenicity of hIAPP has been related to amino acids in the sequence (20-29) (Ashburn \& Lansbury, 1993; Moriarty \& Raleigh, 1999; Westermark et al., 1990). Moreover, the decapeptide hIAPP(20-29) has been found to form fibrils that most likely contain the peptide in a highly pleated antiparallel $\beta$-sheet conformation and in a morphology that is similar to the fibrils formed by the complete hIAPP sequence (Glenner et al., 1988; Griffiths et al., 1995; Moriarty \& Raleigh, 1999). Thus, hIAPP(20-29) has been the shortest reported hIAPP sequence with fibrillogenic potential to date (Glenner et al., 1988; Moriarty \& Raleigh, 1999). We have recently shown that a conformational transition of soluble IAPP into $\beta$-sheets precedes in vitro hIAPP insolubilization into fibrils (Kayed et al., 1999). In addition, we have shown that the kinetics of hIAPP amyloid formation are consistent with the

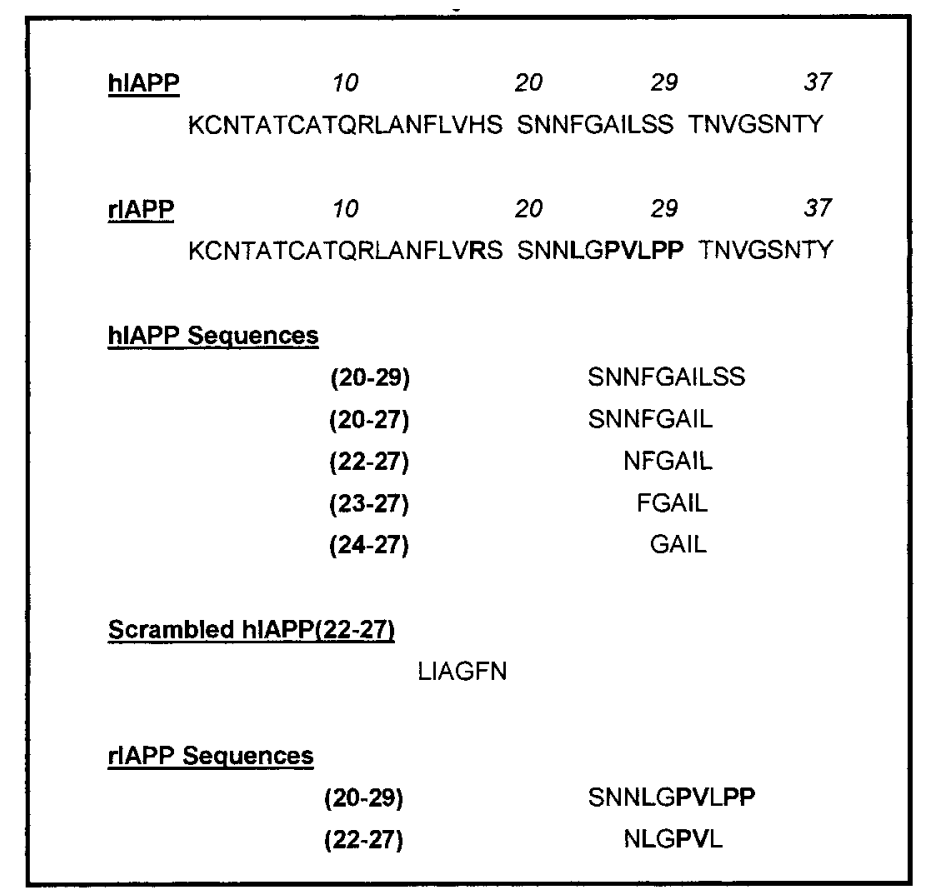

Scheme 1. Primary sequence of hIAPP, rIAPP, and the synthetic peptide sequences that were synthesized and studied. hIAPP and rIAPP contain a C-terminal amide and a disulfide bridge between Cys2 and Cys7 that are not shown. Residues in bold in rIAPP or in the partial rIAPP sequences indicate those amino acids of rIAPP that differ from hIAPP. 
nucleation-dependent polymerization mechanism (Jarrett \& Lansbury, 1993; Kayed et al., 1999).

Here, we focus on the identification of the shortest sequence of hIAPP which is able to self-assemble into $\beta$-sheets and amyloid. Secondary structure prediction analysis of the (20-29) region of hIAPP was performed first and the sequences that were predicted to form $\beta$-sheet structures and appropriate control-sequences were synthesized. Kinetics of insoluble fibril formation were studied by turbidity measurements at $400 \mathrm{~nm}$ and their fibrillogenic potentials evaluated by electron microscopy (EM), atomic force microscopy (AFM), and the Congo red (CR) staining method. Conformations of insoluble peptide aggregates were studied by Fourier transform infrared (FT-IR) spectroscopy. Finally, the effect of the short hIAPP sequences on cell viability of a pancreatic cell line was examined.

\section{Results}

\section{Identification of minimum length IAPP sequences with fibrillogenic potential}

We first performed secondary structure prediction analysis of hIAPP(20-29) (SNNFGAILSS), which was established to represent an amyloidogenic sequence of IAPP (Ashburn et al., 1992; Ashburn \& Lansbury, 1993; Moriarty \& Raleigh, 1999; Westermark et al., 1990), by the method described by Chou \& Fasman (1978), and found that hIAPP(23-27) (FGAIL) could potentially be the shortest sequence with $\beta$-sheet-forming potential. By contrast, no $\beta$-sheet-forming potential was predicted for the corresponding rat sequence, rIAPP(23-27) (LGPVL). Since the amyloidogenicity of a peptide sequence has been described to be often closely related to its $\beta$-sheet-forming propensity (Ashburn et al., 1992; Ashburn \& Lansbury, 1993; Jarrett et al., 1993; Lansbury, 1992; Moriarty \& Raleigh, 1999), we hypothesized that the sequence hIAPP(23-27) (FGAIL) could be fibrillogenic. Such an assumption was supported by rotational resonance solid-state NMR ( ${ }^{2}$-SSNMR) studies that have suggested that the basic unit of the hIAPP(20-29) (SNNFGAILSS) fibril may contain the FGAIL sequence in a self-assembled, intermolecular $\beta$-sheet configuration (Griffiths et al., 1995).

We synthesized hIAPP(23-27) (FGAIL) as well as the longer and shorter analogs hIAPP(22-27) (NFGAIL) and hIAPP(24-27) (GAIL), respectively (Scheme 1). Sequences hIAPP(20-29) (SNN FGAILSS), a scrambled version of hIAPP(22-27) (LIAGFN), rIAPP(20-29) (SNNLGPVLPP), and rIAPP(22-27) (NLGPVL) were also synthesized and used as controls for $\beta$-sheet-forming and amyloidogenic or non-amyloidogenic sequences, respectively (Westermark et al., 1990).

We then tested the fibrillogenic potential of these peptides by EM and AFM. Following aging of a highly concentrated aqueous solution $(3.7-9.3 \mathrm{mg} /$ $\mathrm{ml}$, four to six days incubation time in phosphate buffer $(\mathrm{pH} 7.4)$ or in water), the tetrapeptide hIAPP(24-27) (GAIL) remained soluble. AFM examination confirmed that no fibrils were present in the hIAPP(24-27) (GAIL) solutions. Instead, round and punctuate aggregates formed when the solution was allowed to dry (Figure 1(a)). By contrast, supersaturated and aged aqueous suspensions of hIAPP(23-27) (FGAIL) and hIAPP(22-27) (NFGAIL) (tested apparent peptide concentrations were $2.6-5.2 \mathrm{mg} / \mathrm{ml}$ for FGAIL and 3.2-6.4 $\mathrm{mg} / \mathrm{ml}$ for NFGAIL, in phosphate buffer $(\mathrm{pH} 7.4)$, or water, four to six days incubation time) were found to consist exclusively of amyloid-like fibrils and fibril bundles (Figures 1(b) and (c), and 2(a) and (b)). Although these two peptide sequences differ by only one residue, their fibrillar assemblies were completely different. hIAPP(23-27) (FGAIL) fibrils generally aligned laterally with each other to yield very long $(>3 \mu \mathrm{m})$ and broad $(>300 \mathrm{~nm})$ ribbon-like fibril bundles (Figures 1(b) and 2(a) and (b)). By contrast, hIAPP(22-27) (NFGAIL) filaments coiled along each other and resulted in fibrils with properties that have been well described for amyloids, i.e. an axial helical periodicity (about $200 \mathrm{~nm}$ ) (Goldsbury et al., 1997, 1999; Harper et al., 1997a,b; Stine et al., 1996). Of note, no propensity towards a parallel alignment, as seen with the hIAPP(23-27) (FGAIL) filaments, was observed for hIAPP(22-27) (NFGAIL) (Figure 1(c)). Judging from the EM measurements, hIAPP(22-27) (NFGAIL) fibrils had diameters of about 15 to $20 \mathrm{~nm}$. However, it should be noted that the observed branching and coiling features of the hIAPP(22-27) (NFGAIL) fibrils (Figure 1(c)) suggested that the diameters measured represented an assembly of at least two filaments (Harper et al., 1997a,b). A majority of isolated hIAPP(23-27) (FGAIL) fibrils, which may also represent an assembly of at least two filaments, had diameters of about $17 \mathrm{~nm}$ according to AFM.

Aged and saturated solutions of hIAPP(20-27) (SNNFGAIL) and hIAPP(20-29) (SNNFGAILSS) also formed fibrils and fibril bundles (Figure 1(d) and (e)). Fibrils of hIAPP(20-27) (SNNFGAIL) showed a similar helical coiling around each other as seen for the hIAPP(20-27) (NFGAIL) fibrils and had diameters of about 6 to $10 \mathrm{~nm}$, as estimated by EM. By contrast, filaments of hIAPP(20-29) (SNNFGAILSS) had a strong propensity to laterally self-assemble into a net of broad ribbons. No fibril formation was observed in aged incubations of highly concentrated solutions $(6.4 \mathrm{mg} / \mathrm{ml}$ or $10 \mathrm{mM})$ of the scrambled hIAPP(22-27) control peptide LIAGFN. These solutions, when dried, exclusively consisted of amorphous aggregates (Figure 1(f)). Similarly, highly concentrated solutions of the soluble rat sequences $\operatorname{rIAPP}(22-27)$ (NLGPVL) $(6.1 \mathrm{mg} / \mathrm{ml}$ or $10 \mathrm{mM})$ (Figure $1(\mathrm{~g}))$ and rIAPP(20-29) (SNNLGPVLPP) $(10 \mathrm{mg} / \mathrm{ml}$ or $10 \mathrm{mM}$ ) (data not shown) consisted of amorphous aggregates only. 

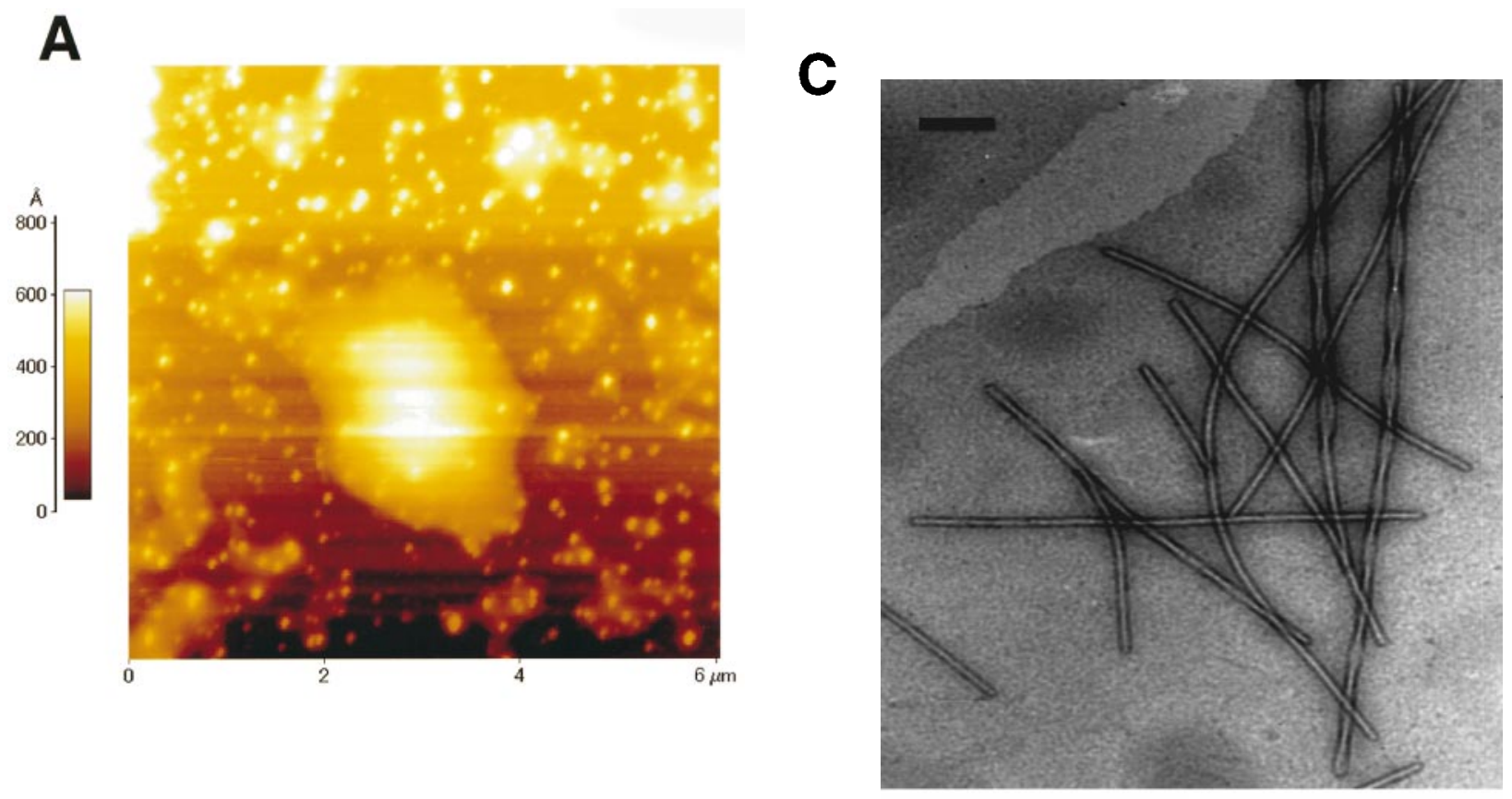

\section{B}
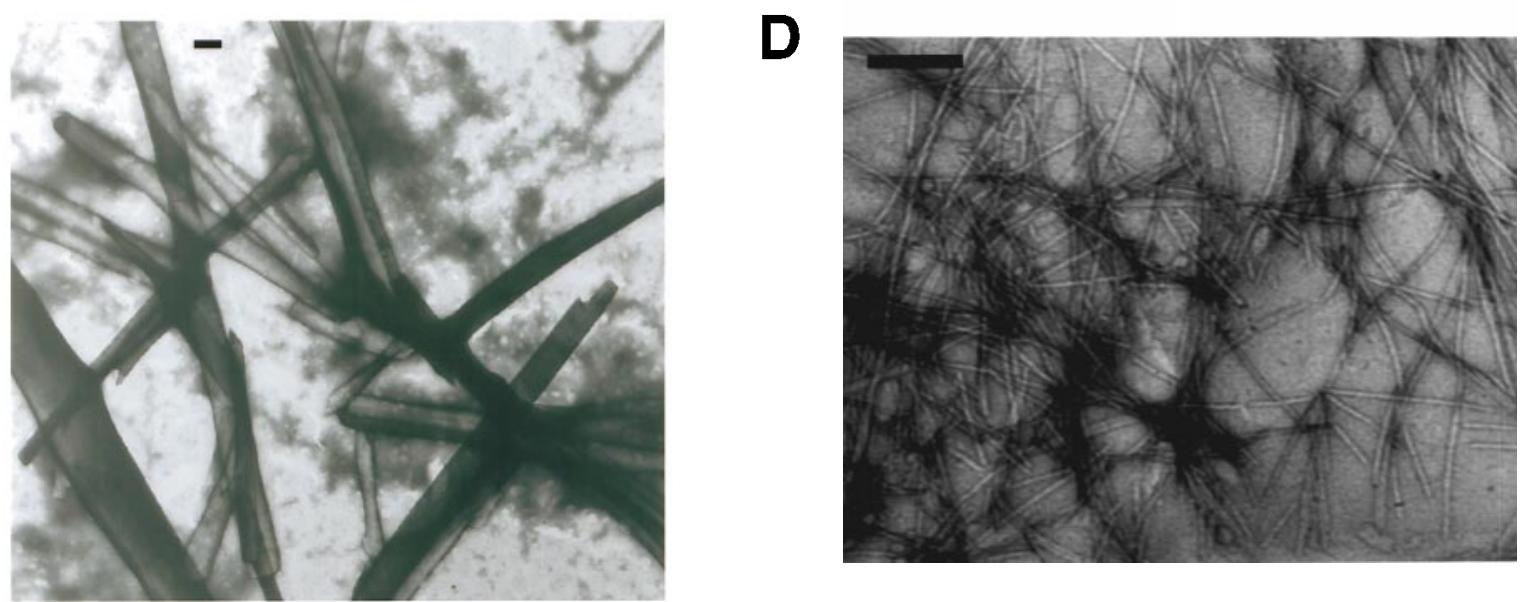

Figure 1 (legend shown on p. 1057)

We then applied the CR staining method combined with polarization microscopy to test for amyloidogenicity of the IAPP sequences. Amyloid fibrils in general, and fibrillar hIAPP in particular, bind CR and exhibit a gold/green birefringence under polarized light (Cooper, 1974; Lansbury, 1992). Aged hIAPP(23-27) (FGAIL) and hIAPP(2227) (NFGAIL) suspensions $(2.6-5.2 \mathrm{mg} / \mathrm{ml}$ for FGAIL and $3.2-6.4 \mathrm{mg} / \mathrm{ml}$ for NFGAIL, in phosphate buffer ( $\mathrm{pH} 7.4$ ), aged for four days) bound $\mathrm{CR}$ and exhibited the characteristic green/gold birefringence (Figure 3(a) for normal field and (b) for polarized light microscopy of hIAPP(23-27) (FGAIL), and Figure 3(c) for normal field and (d) for polarized microscopy of hIAPP(22-27) (NFGAIL)). hIAPP(20-27) (SNNFGAIL) also stained with $\mathrm{CR}$ and showed strong birefringence (not shown). As a control, aged, supersaturated solutions of hIAPP(20-29) (SNNFGAILSS) were also examined and were found to exhibit strong green/gold birefringence, whereas no CR binding was found for aged solutions of $\operatorname{rIAPP}(22-27)$ (NLGPVL) and rIAPP(20-29) (SNNLGPVLPP) (not shown). Interestingly, aged and highly concentrated solutions of hIAPP(24-27) (GAIL) (25 mM or $9.3 \mathrm{mg} / \mathrm{ml}$ ), when allowed to dry, yielded long needles that were visible by light microscopy. These needles appeared birefringent with and 

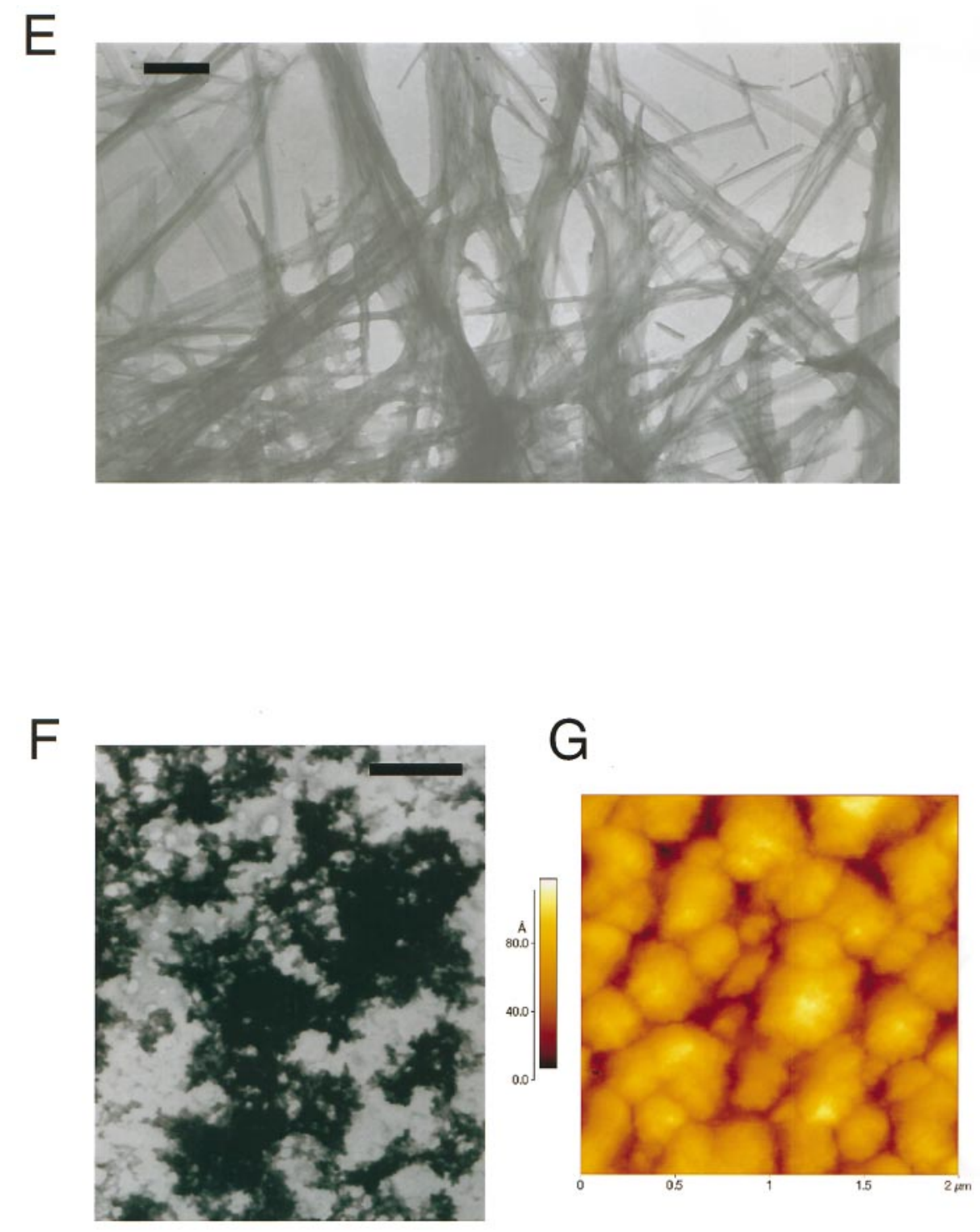

Figure 1. Atomic force (AFM) and electron microscopic examination (EM) of incubations of synthetic IAPP sequences. (a) AFM image $(6 \mu \mathrm{m} \times 6 \mu \mathrm{m})$ of aged hIAPP(24-27) (GAIL) solution (10 mM) prepared as described in Materials and Methods. The vertical bar on the left side of the Figure indicates the heights of the measured objects. (b) Electron micrograph of insoluble aggregates of hIAPP(23-27) (FGAIL) formed in an aged peptide solution. The apparent peptide concentration was $5.2 \mathrm{mg} / \mathrm{ml}$ in phosphate buffer $(\mathrm{pH} \mathrm{7.4)}$, and incubation time was three days The scale bar represents $200 \mathrm{~nm}$. (c) Electron micrograph of insoluble aggregates of hIAPP(22-27) (NFGAIL) formed in an aged peptide solution. The apparent peptide concentration was $6.4 \mathrm{mg} / \mathrm{ml}$ in phosphate buffer ( $\mathrm{pH} 7.4$ ), and incubation time was three days. The scale bar represents $200 \mathrm{~nm}$. (d) Electron micrograph of insoluble aggregates of hIAPP(20-27) (SNNFGAIL) formed in an aged peptide solution. The apparent peptide concentration was $4.2 \mathrm{mg} / \mathrm{ml}$ in phosphate buffer ( $\mathrm{pH} 7.4$ ), and incubation time was three days. The scale bar represents $1 \mu \mathrm{m}$. (e) Electron micrograph of insoluble aggregates of hIAPP(20-29) (SNNFGAILSS) formed in an aged peptide solution. The apparent peptide concentration was $0.2 \mathrm{mg} / \mathrm{ml}$ in phosphate buffer $(\mathrm{pH} 7.4)$, and incubation time was three days. The scale bar represents $1 \mu \mathrm{m}$. (f) Electron micrograph of aged solution of scrambled hIAPP(22-27) (LIAGFN). The apparent

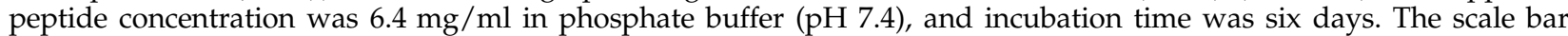
represents $1 \mu \mathrm{m}$. (g) AFM image $(2 \mu \mathrm{m} \times 2 \mu \mathrm{m}$ ) of aged rIAPP(22-27) (NLGPVL) solution $(6.1 \mathrm{mg} / \mathrm{ml}) \mathrm{prepared}$ as described in Materials and Methods. 

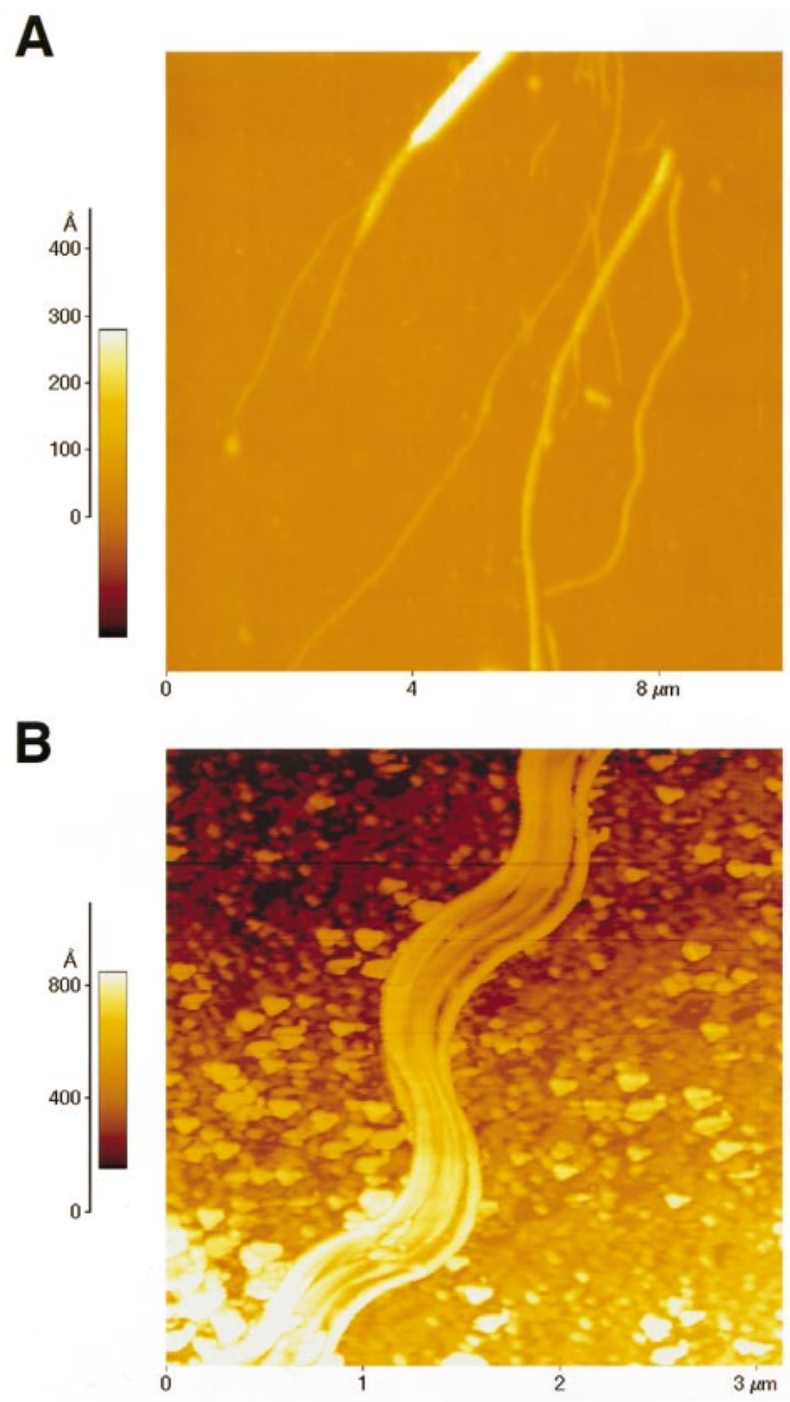

Figure 2. Atomic force microscopic examination (AFM) of fibrillar aggregates of hIAPP(23-27) (FGAIL). (a) AFM image $(10 \mu \mathrm{m} \times 10 \mu \mathrm{m})$ of single fibrils of an aged hIAPP(23-27) (FGAIL) solution (apparent peptide concentration $2.6 \mathrm{mg} / \mathrm{ml}$ ) prepared as described in Materials and Methods. (b) AFM image $(3.1 \mu \mathrm{m} \times 3.1$ $\mu \mathrm{m})$ of ribbon-like fibril bundles of the aged hIAPP(2327) (FGAIL) solution (see (a)). The vertical bar on the left side of the Figure indicates the heights of the measured objects.

without CR staining under polarized light (Figure 3(e) for normal field and (f) for polarized microscopy).

Taken together, the results of the EM, AFM, and $\mathrm{CR}$ analyses strongly suggested that hIAPP(23-27) (FGAIL) is the shortest hIAPP sequence necessary for amyloid formation.

\section{Aggregation kinetics of the hIAPP sequences}

Aggregation of several amyloid-forming polypeptides in vitro has been suggested to proceed by nucleation-dependent polymerization (Ashburn \& Lansbury, 1993; Harper \& Lansbury, 1997; Jarrett et al., 1993; Jarrett \& Lansbury, 1993). The existence of a lag-time prior to protein aggregation, which is partially or completely eliminated by the addition of preformed aggregates or seeds, is a characteristic feature of this mechanism. To study self-assembly of our amyloidogenic sequences, we followed their aggregation and insolubilization kinetics by turbidity measurements at $400 \mathrm{~nm}$ (Figure 4) (Ashburn \& Lansbury, 1993; Harper \& Lansbury, 1997; Jarrett et al., 1993; Jarrett \& Lansbury, 1993). In another series of experiments, the results of the turbidity assays were independently confirmed by the CR binding assay (data not shown) (Klunk et al., 1989a,b).

For the kinetic aggregation assays, several solvents for preparation of stock solutions and various peptide concentrations were tested to obtain reproducible aggregation kinetics. This was necessary due to the various experimental factors that may strongly affect aggregation kinetics of supersaturated solutions, which are inherently metastable (Harper \& Lansbury, 1997; Jarrett \& Lansbury, 1993; Kayed et al., 1999). For the preparation of the peptide stocks, acetonitrile (ACN) and 1,1,1,3,3,3-hexafluoro-2-propanol were among those examined. As hIAPP(20-27) (SNNFGAIL) and hIAPP(20-29) (SNNFGAILSS) were insoluble in these solvents at the required concentrations, stock solutions of all peptide sequences were eventually prepared in dimethyl sulfoxide (DMSO) and used immediately to avoid formation of pre-aggregated peptide seeds (Jarrett \& Lansbury, 1993). DMSO is broadly applied as a disaggregating solvent, especially for the preparation of stock solutions of amyloidogenic peptides including sequences of hIAPP (Ashburn \& Lansbury, 1993; Harper et al., 1997b; Jarrett et al., 1993). However, the possibility that stock solutions prepared in DMSO may also contain minute amounts of seeds cannot be completely excluded. Filtering of the solutions was not possible due to strong nonspecific binding of the peptides to various filter membranes. Yet, the observed concentration dependence of the lag-time (data not shown) and the reproducibility of our results indicated that our fresh stock solutions most likely did not contain aggregation nuclei.

The kinetic profiles of insoluble amyloid formation observed for all short sequences were strongly indicative of a nucleation-dependent polymerization mechanism (Jarrett \& Lansbury, 1993). After a lag-time of 30 hours, hIAPP(23-27) (FGAIL) $(2.6 \mathrm{mg} / \mathrm{ml}$ in phosphate buffer and $4 \%$ DMSO, $\mathrm{pH} 7.4$ ) rapidly self-assembled into insoluble amyloid fibrils (Figure 4). Aggregation of hIAPP(22-27) (NFGAIL) at an identical apparent molar concentration $(3.2 \mathrm{mg} / \mathrm{ml})$ exhibited a significantly shorter lag-time of only 42 minutes (Figure 4), indicating a lower kinetic solubility for this sequence. hIAPP(20-27) (SNNFGAIL) and the strongly amyloidogenic sequence hIAPP(20-29) 

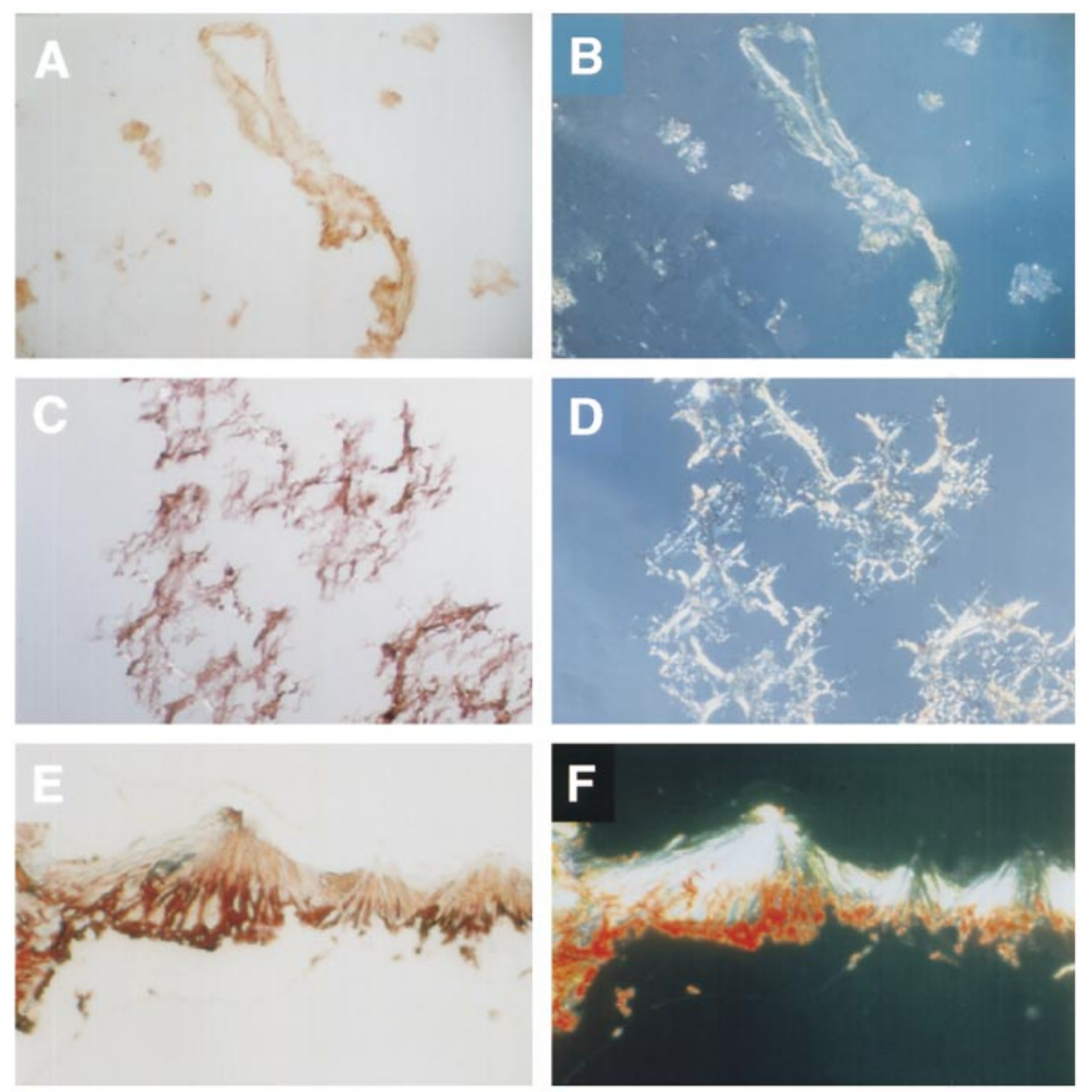

Figure 3. Examination of the amyloidogenic nature of partial hIAPP fragments by the Congo red (CR) binding assay. Normal field microscopic examination of aged solutions of (a) hIAPP(23-27) (FGAIL), (c) hIAPP(22-27) (NFGAIL), and (e) hIAPP(24-27) (GAIL) following staining with CR is shown. Microscopic examination under polarized light of (b) hIAPP(23-27) (FGAIL), (d) hIAPP(22-27) (NFGAIL), and (f) hIAPP(24-27) (GAIL) is also shown. Supersaturated solutions were prepared and aged for four days as described in Materials and Methods.

(SNNFGAILSS) immediately aggregated under the above conditions (Figure 4) (Ashburn \& Lansbury, 1993). By contrast, hIAPP(24-27) (GAIL) was highly soluble in aqueous buffer and did not aggregate under these conditions neither at fourfold higher molar concentrations than those applied for the other sequences (Figure 4). Of note, because the molecular mass of the various self-associated peptide species is unknown, the concentrations of the amyloidogenic sequences are generally presented as mass per volume measures. To compare the biophysical properties (fibril- and $\beta$-sheet-forming potentials, solubilities and cytotoxicities) of the different peptide sequences, solutions or suspensions of identical "apparent" molar concentrations were applied, indicated by the use of molar concentration units. Molarities were calculated based on the molecular mass of the monomers, assuming that the peptides were monomeric and completely soluble.

Kinetic aggregation studies of the amyloidogenic fragments at various peptide concentrations indi- cated that the length of the lag-time was inversely related to the apparent peptide concentration (data not shown), which is another characteristic feature of nucleation-dependent polymerization (Jarrett \& Lansbury, 1993). Of importance, the observed lagtimes of aggregation for hIAPP(23-27) (FGAIL) and (22-27) (NFGAIL) were immediately eliminated by seeding, further adding to the notion that amyloid formation by the short hIAPP sequences was nucleation-dependent (Figure 5(a) and (b)).

In agreement with previous reports (Jarrett \& Lansbury, 1993), the thermodynamic solubilities of the hIAPP sequences were found to depend strongly on the specific peptide sequence. Thermodynamic solubilities were determined by quantification of the amount of soluble peptide at the point of thermodynamic equilibrium which was usually after four days following the beginning of the aggregation experiment (Ashburn \& Lansbury, 1993; Jarrett et al., 1993; Jarrett \& Lansbury, 1993). In the post-nucleation equilibrium, hIAPP(23-27) (FGAIL) exhibited the highest thermodynamic 


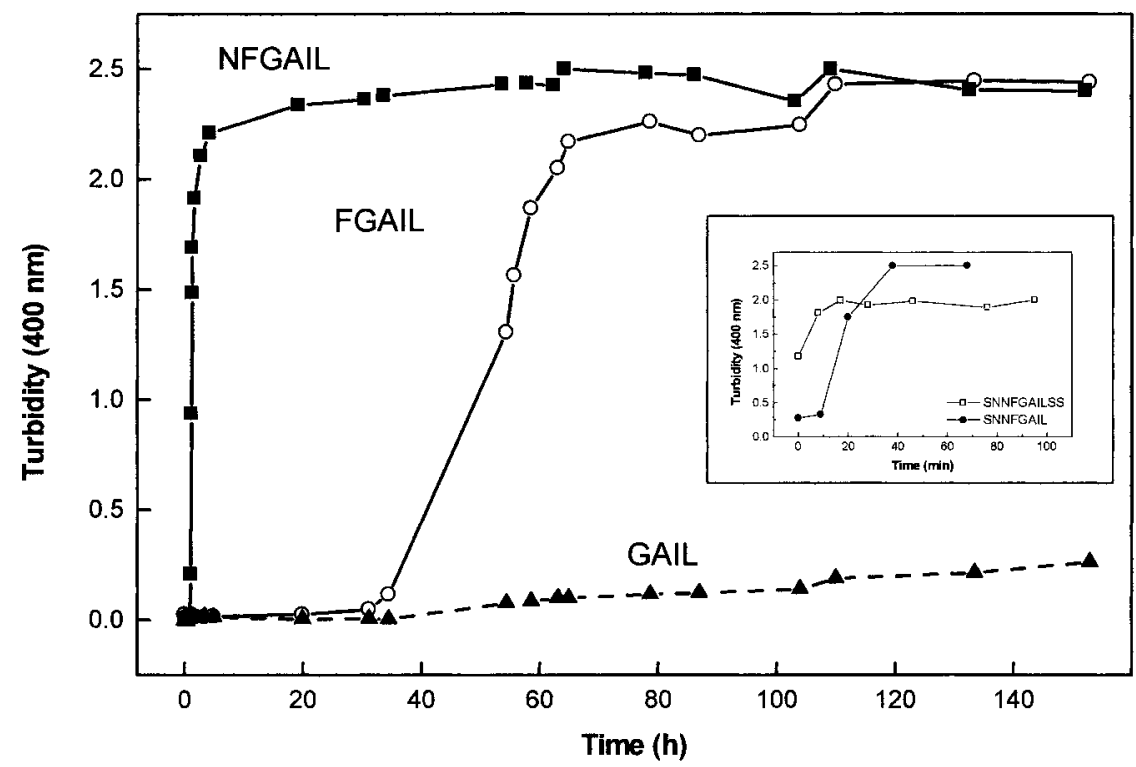

Figure 4. Kinetics of insoluble amyloid formation of partial hIAPP sequences as followed by turbidity at $400 \mathrm{~nm}$. Turbidity of aqueous solutions of hIAPP(24-27) (GAIL), (23-27) (FGAIL), and (22-27) (NFGAIL) in $10 \mathrm{mM}$ phosphate buffer ( $\mathrm{pH} 7.4)$, and $4 \%$ DMSO (apparent peptide concentrations were $5 \mathrm{mM}$ ) prepared as described in Materials and Methods was followed for several hours. Inset: Kinetics of aggregation of hIAPP sequences (20-27) (SNNFGAIL) and (20-29) (SNNFGAILSS) under the same experimental conditions as for the shorter sequences are shown (time-scale: minutes). Turbidity of aqueous solutions (apparent peptide concentrations were $5 \mathrm{mM}$ ) was measured and solutions prepared as described in Materials and Methods. Data are from one representative experiment of at least three performed.

solubility $\quad(1.4( \pm 0.2) \mathrm{mg} / \mathrm{ml})$ and $\mathrm{hIAPP}(20-29)$ (SNNFGAILSS) the lowest one $(0.3( \pm 0.1) \mathrm{mg} / \mathrm{ml})$, while hIAPP(20-27) (SNNFGAIL) exhibited a thermodynamic solubility that was similar to hIAPP $(20-29) \quad(0.5( \pm 0.1) \mathrm{mg} / \mathrm{ml}) \quad($ mean $( \pm$ SEM $)$ of at least three independent aggregation assays). Interestingly, a $40 \%$ higher insolubility on a molar basis was found for hIAPP(22-27) (NFGAIL) (thermodynamic solubility: $1.2( \pm 0.2) \mathrm{mg} / \mathrm{ml}$ ), as compared to hIAPP(23-27) (FGAIL).
A

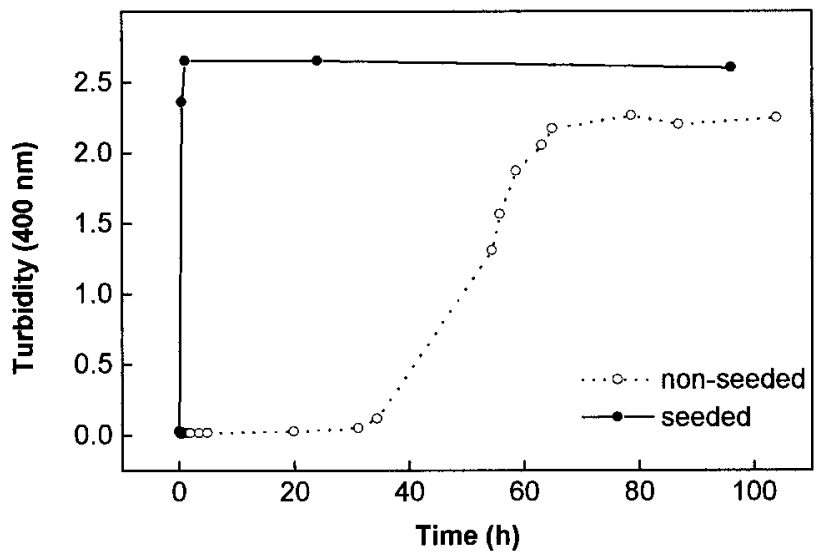

B

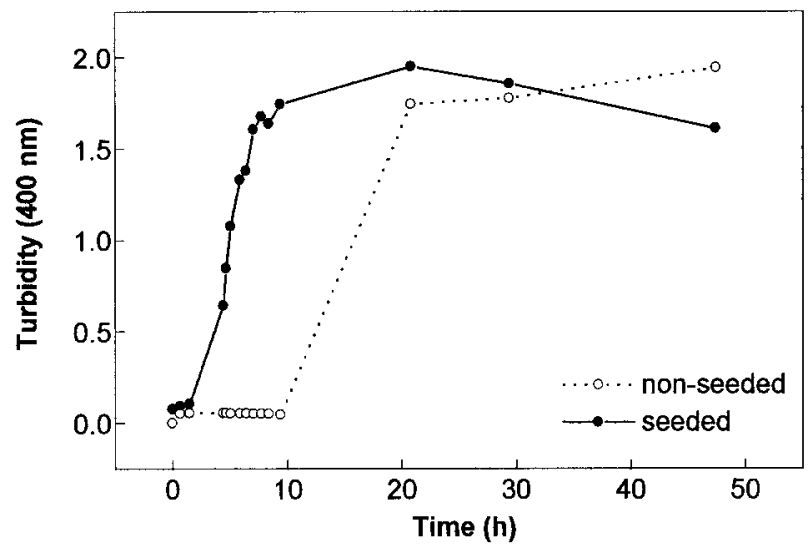

Figure 5. Nucleation of amyloid formation by hIAPP sequences (23-27) (FGAIL) and (22-27) (NFGAIL) via addition of traces of preformed fibrils. Kinetics of amyloid formation are followed by turbidity measurement at $400 \mathrm{~nm}$ for seeded and non-seeded (a) hIAPP(23-27) (FGAIL) $(2.6 \mathrm{mg} / \mathrm{ml})$ and (b) hIAPP(22-27) (NFGAIL) (2.4 mg/ml) as indicated. Seeding was performed with $10 \%$ preformed (a) hIAPP(23-27) (FGAIL) fibrils and (b) hIAPP(22-27) (NFGAIL) fibrils as described in Materials and Methods. Data are from one representative experiment of at least three performed. 


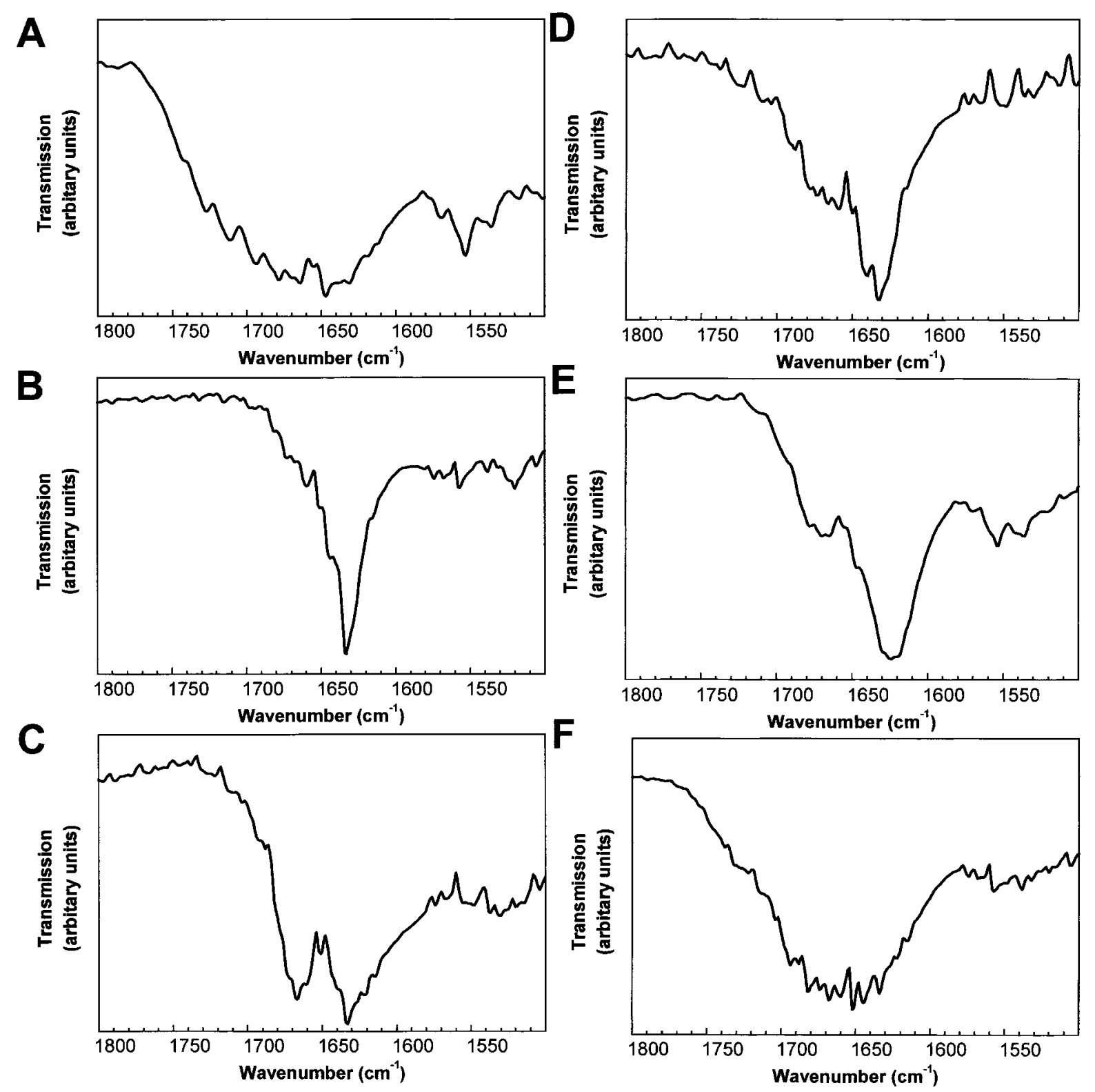

Figure 6. Secondary structure of fibrillar aggregates of partial hIAPP sequences, aged hIAPP(24-27) (GAIL) and rIAPP(22-27) (NLGPVL) as assessed by Fourier transform infrared spectroscopy (FT-IR). (a) Spectrum of an aged hIAPP(24-27) (GAIL) solution prepared and measured as described in Materials and Methods. (b) Insoluble fibrils of hIAPP(23-27) (FGAIL), (c) hIAPP(22-27) (NFGAIL), (d) hIAPP(20-27) (SNNFGAIL), and (e) hIAPP(20-29) (SNNFGAILSS) were collected from kinetic aggregation experiments and FT-IR spectra were measured as described in Materials and Methods. (f) Spectrum of an aged rIAPP(22-27) (NLGPVL) solution prepared and measured as described in Materials and Methods.

\section{Conformation of the hIAPP sequences in their fibrillar state as determined by FT-IR}

FT-IR spectroscopic studies of the aggregates of the amyloidogenic partial sequences and also of highly concentrated and aged $(3.7 \mathrm{mg} / \mathrm{ml}$ or $10 \mathrm{mM}$, incubation time of four days) solutions of hIAPP(24-27) (GAIL) were then performed. The fibrillar aggregates were obtained from the kinetic aggregation assays and were collected after four days of aggregation. FT-IR spectra typical for a random coil structure mixed with various different conformations were recorded for aged hIAPP(24-27) (GAIL) solutions (Figure 6(a)). By contrast, a sharp absorbance maximum at $1633 \mathrm{~cm}^{-1}$ was found in the spectrum of hIAPP(2327) (FGAIL) fibrils. Such an absorbance is typically assigned to $\beta$-sheet structures (Krimm \& Bandekar, 1986; Lansbury, 1992) (Figure 6(b)). hIAPP(22-27) 
A

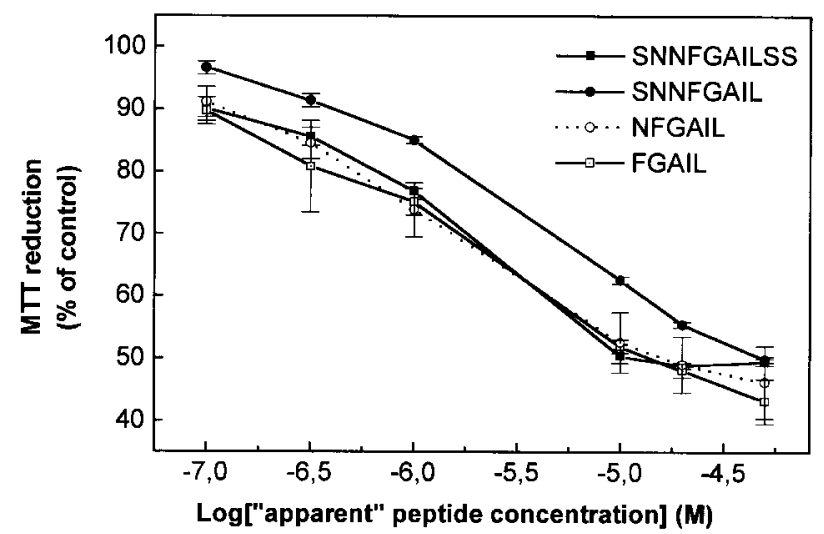

B

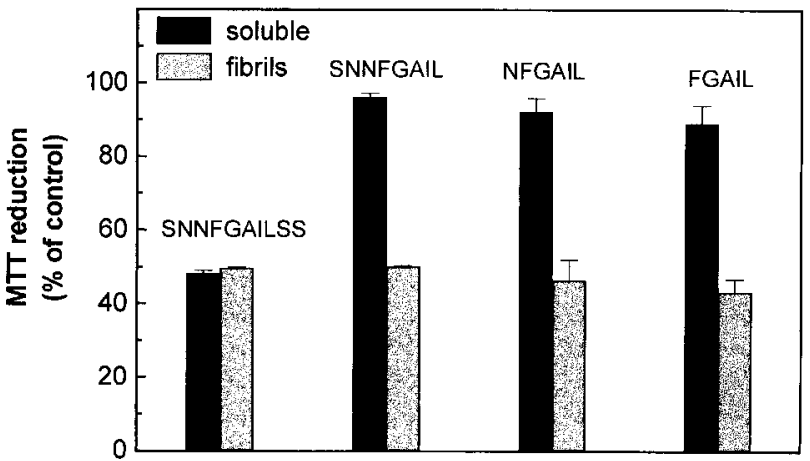

Figure 7. (a) Cytoxicity of fibrillar aggregates of partial sequences of hIAPP as indicated. Various concentrations of fibrillar aggregates of hIAPP(23-27) (FGAIL), hIAPP(22-27) (NFGAIL), hIAPP(20-27) (SNNFGAIL), and hIAPP(20-29) (SNNFGAILSS) were added to RIN5fm cells that were plated at a density of $5 \times 10^{5}$ cells $/ \mathrm{ml}$. Following a 20 hours incubation, cell viability was assessed by measuring the cellular reduction of MTT. (b) Comparison of the cytotoxicities of soluble (fresh dissolved) versus the fibrillar forms of the hIAPP fragments as indicated. Lyophilized peptides corresponding to sequences hIAPP(23-27) (FGAIL), hIAPP(22-27) (NFGAIL), hIAPP(20-27) ((SNNFGAIL), and hIAPP(20-29) (SNNFGAILSS) were dissolved in cell culture medium at an apparent concentration of $500 \mu \mathrm{M}$ and then immediately added to the cells at an apparent final concentration of $50 \mu \mathrm{M}$. Fibrillar aggregates were also applied onto cells at apparent concentrations of $50 \mu \mathrm{M}$. Following incubation, cytotoxicities were assessed as described in (a). Data are percentages of control values (vehicle alone) and are the mean ( \pm SEM) of three independent experiments with each experiment performed in multiple replicates $(n=6)$ except for the data of hIAPP(20-27) which are derived from one representative experiment performed in $n=12$ replicates.

(NFGAIL) fibrils produced a spectrum with a markedly broader absorbance maximum at $1633 \mathrm{~cm}^{-1}$ and a strong shoulder at $1666 \mathrm{~cm}^{-1}$, indicating the presence of $\beta$-structures mixed with significant amounts of non- $\beta$ structures, i.e. random coil and turns (Figure 6(c)). The spectra of the fibrils of hIAPP(20-27) (SNNFGAIL) and hIAPP(2029) (SNNFGAILSS) had pronounced maxima at $1633 \mathrm{~cm}^{-1}$ and $1625 \mathrm{~cm}^{-1}$, respectively, suggesting significant $\beta$-sheet contents (Figure 6(d) and (e)) (Ashburn et al., 1992; Ashburn \& Lansbury, 1993; Glenner et al., 1988; Lansbury, 1992; Moriarty \& Raleigh, 1999). By contrast, aged and highly concentrated solutions of the reported non-amyloidogenic rIAPP(20-29) (SNNLGPVLPP) (10 mM or $10.1 \mathrm{mg} / \mathrm{ml}$ in ${ }^{2} \mathrm{H}_{2} \mathrm{O}$ ) (not shown) and $\operatorname{rIAPP}(22-$ 27) (NLGPVL) $\left(10 \mathrm{mM}\right.$ or $6.1 \mathrm{mg} / \mathrm{ml}$ in $\left.{ }^{2} \mathrm{H}_{2} \mathrm{O}\right)$, (Figure 6(f)), gave FT-IR spectra that indicated that non- $\beta$ conformations were predominant.

\section{Effect of the hIAPP fragments on the viability of a pancreatic $\beta$-cell line}

There are several lines of evidence suggesting an association between the pathology of the various amyloidoses and the cytotoxicity of the fibrillar forms of the respective amyloid-forming peptides, including $\beta$-amyloid peptide $(\mathrm{A} \beta)$, prion protein, and hIAPP (Forloni et al., 1994; Iversen et al., 1995; Lorenzo et al., 1994; Lorenzo \& Yankner, 1994; Pike et al., 1991, 1995). We used the insulin-producing pancreatic cell line RIN5mf (Nishi et al., 1989) to test the cytotoxic effect of fragments hIAPP(23-27) (FGAIL), (22-27) (NFGAIL), (20-27) (SNNFGAIL), and (20-29) (SNNFGAILSS). In preliminary studies, a strong cytotoxic effect of the complete hIAPP sequence on this cell line was found (data not shown); its effective apparent concentration that caused $50 \%$ cell damage $\left(\mathrm{EC}_{50}\right)$ following a 20 hours incubation was $1.2 \mathrm{nM}$. For the assessment of peptide toxicity, an assay based on the cellular reduction of the dye 3-[4,5-dimethylthiazol-2-yl]2,5-diphenyltetrazolium bromide (MTT) was used (Kapurniotu et al., 1998; Schubert et al., 1995; Shearman et al., 1995, 1994).

We first tested the effect of preformed fibrillar aggregates of hIAPP(23-27) (FGAIL), (22-27) (NFGAIL), (20-27) (SNNFGAIL), and (20-29) (SNNFGAILSS) obtained from the kinetic aggregation experiments (see above). Fibrillar aggregates were collected after aggregations had reached a thermodynamic equilibrium (four days), quantified, and added to the cells. We found significant cytotoxicities for the preformed fibrillar aggregates of the known amyloidogenic sequence hIAPP(2029) (SNNFGAILSS) as well as for the aggregates of hIAPP(23-27) (FGAIL) and (22-27) (NFGAIL) that were similarily cytotoxic to hIAPP(20-29) (Figure 7(a)). Of note, cytotoxicities of these peptides were about 1000 -fold lower on a molar basis 
than that of the complete hIAPP sequence. The aggregates of hIAPP (20-27) (SNNFGAIL) were slightly less toxic than the aggregates of the three other peptide fragments (Figure 7(a)). As a negative control, sequence LIAGFN that was previously found to be non-amyloidogenic was tested following aging and no cytotoxicity was found. To control for possible reported effects of DMSO on cytotoxicity (Mattson et al., 1992), peptide fibrils were also prepared by dissolving or suspending the peptides in $\mathrm{H}_{2} \mathrm{O}$ followed by aging for four days prior to application onto the cells. Under these conditions, the same cytotoxicities were observed as for the peptide stocks prepared in DMSO.

We then tested the cytotoxic effect of the freshly dissolved peptides. Peptide stock solutions of the partial sequences were prepared by directly dissolving the lyophilized peptides in cell medium and at an apparent concentration of $500 \mu \mathrm{M}$. While the solutions of peptides (24-27) (GAIL), (23-27) (FGAIL), (22-27) (NFGAIL), and (20-27) (SNNFGAIL) did not contain fibrils at the time point of their preparation, the stock solutions of hIAPP and (20-29) (SNNFGAILSS) already contained some fibrillar aggregates due to their low kinetic solubilities. The absence or presence of fibrils at the time of preparation of the stock solutions was verified by EM (not shown). Incubation of the cells with freshly dissolved hIAPP(24-27) (GAIL), (23-27) (FGAIL), (22-27) (NFGAIL), and (20-27) (SNNFGAIL) for about 20 hours did not affect cell viability, whereas non-aged but fibrilcontaining hIAPP(20-29) (SNNFGAILSS) was as cytotoxic as its fibrillar form (Figure 7(b)). No insoluble peptide aggregates on or between the cells could be detected by light microscopic examination of the incubations with hIAPP(23-27) (FGAIL), (2227) (NFGAIL), and (20-27) (SNNFGAIL), whereas significant amounts of such aggregates were observed in the hIAPP(20-29) (SNNFGAILSS) or hIAPP incubations. Thus, it is likely that peptides hIAPP(23-27) (FGAIL), (22-27) (NFGAIL), and (20-27) (SNNFGAIL), due to their high degree of solubility and their long aggregational lag-times, remained in their soluble forms during the 20 hour incubation period, suggesting that the soluble forms are likely non-toxic.

\section{Discussion}

There is increasing evidence suggesting a direct association of aggregation and fibril formation by amyloid-forming polypeptides with the pathologic sequelae of amyloidosis-related diseases, including prion-protein related encephalopathies, AD, and type II diabetes (Clark et al., 1987; Forloni et al., 1994; Iversen et al., 1995; Lorenzo et al., 1994; Lorenzo \& Yankner, 1994; Pike et al., 1991, 1995; Schubert et al., 1995; Thomas et al., 1995). Amyloid consists of polypeptide chains that are predominantly in a $\beta$-sheet conformation (Ashburn et al.,
1992; Ashburn \& Lansbury, 1993; Gasset et al., 1992; Hilbich et al., 1991; Inouye et al., 1993; Jarrett et al., 1993; Lansbury, 1992; Zhang \& Rich, 1997). The $\beta$-sheet-forming propensity of a peptide chain has been shown to be closely related to its ability to aggregate into amyloid fibrils (Ashburn et al., 1992; Ashburn \& Lansbury, 1993; Gasset et al., 1992; Glenner et al., 1988; Griffiths et al., 1995; Hilbich et al., 1991; Jarrett et al., 1993; Kapurniotu et al., 1998; Kayed et al., 1999; Kominos, 1995; Lansbury, 1996; Moriarty \& Raleigh, 1999; Pike et al., 1995). Aggregation and amyloid formation by $A \beta$ and hIAPP have been suggested to proceed via a common molecular mechanism that includes a conformational transition from soluble, non-toxic peptide conformers into $\beta$-sheet-containing amyloid precursors (Kayed et al., 1999; Pike et al., 1995; Shen \& Murphy, 1995; Soto \& Frangione, 1995).

Our studies aimed to identify the shortest sequence of hIAPP capable of forming $\beta$-sheets and amyloid. Secondary structure predictions indicated that the sequence hIAPP(23-27) (FGAIL) could be the shortest hIAPP sequence with a $\beta$-sheet-forming potential. In fact, aged suspensions of sequences (23-27) (FGAIL), (22-27) (NFGAIL), (2027) (SNNFGAIL), and (20-29) (SNNFGAILSS) were found to exclusively consist of long fibrils and fibril bundles. While the amyloidogenicity of sequence (20-29) was already known (Ashburn \& Lansbury, 1993; Moriarty \& Raleigh, 1999; Westermark et al., 1990; Glenner et al., 1988), there had been no reports with regard to fibril formation by sequences of amyloidogenic polypeptides as short as the penta- or hexapeptides investigated here. To our knowledge, the shortest sequences that have been reported to be able to form amyloid fibrils consist of at least eight amino acid residues. These are the octapeptide AGAAAAGA of the prion protein and a ten residue peptide of $A \beta$ (Lundberg et al., 1997; Tjernberg et al., 1999).

The filaments of hIAPP sequence (23-27) (FGAIL) showed a strong propensity to laterally self-associate into very broad ribbons, whereas the filaments formed by sequences (22-27) (NFGAIL) and (20-27) (SNNFGAIL) were long and thin and coiled laterally around each other to yield fibril bundles of pronounced axial helical twisting. A lateral helical coiling of filaments around each other has often been described in amyloid fibrils from several different polypeptides, suggesting that this packing might represent a common filament selfassembly mechanism (Goldsbury et al., 1997, 1999; Harper et al., 1997a,b; Stine et al., 1996). On the other hand, studies on $A \beta$ have previously related the formation of ribbon-like arrays to the decreased ability of the filaments to pack laterally in the typical coiled fiber morphology (Fraser et al., 1994). hIAPP has been reported to form fibrils that are characterized by a structural polymorphism, and two mechanisms of hIAPP fibrillar self-assembly have been proposed. These include the lateral assembly into ribbon- or sheet-like arrays and filament coiling into coiled fibrils (Goldsbury et al., 
1997, 1999). Thus, the fibrillar assemblies formed by hIAPP(23-27) (FGAIL) and hIAPP(22-27) (NFGAIL) seem to have formed by both self-association mechanisms in a sequence-dependent manner. The striking differences between the morphologies of the filaments of the two sequences that differ by only one amino acid residue (Asn22) strongly suggest that this residue plays an important role in directing self-assembly and lateral packing of filaments. Such a role could be that its side-chain could be involved in intermolecular side-chain interactions that lead to a filamentstabilizing self-association as previously proposed for protofilament assembly of $\mathrm{A} \beta$ (Fraser et al., 1994). The importance of residue Asn22 for fibril formation was also confirmed by our kinetic aggregation data and has been also pointed out in a very recent study by Moriarty \& Raleigh (1999).

FT-IR spectroscopy of the fibrils of the partial hIAPP sequences suggested that they all contain significant amounts of $\beta$-sheet structure (Ashburn et al., 1992; Ashburn \& Lansbury, 1993; Griffiths et al., 1995). According to the $R^{2}$-SSNMR model of pancreatic amyloid fibrils, hIAPP(23-27) (FGAIL) is strongly constrained in an intermolecular antiparallel $\beta$-sheet, and a number of the sheet-stabilizing intermolecular interactions in hIAPP(20-29) (SNNFGAILSS) fibrils were found to occur between residues in this peptide region (Griffiths et al., 1995). These results are in good agreement with the high $\beta$-sheet and amyloidogenic propensity of hIAPP(23-27) (FGAIL) as found in our work, and suggest that FGAIL could be the core of the hIAPP fibril.

The sequence motif GAIL is common in the two amyloidogenic IAPP sequences from cat and man, and has previously been suggested to be crucial for their amyloidogenicity (Ashburn et al., 1992; Ashburn \& Lansbury, 1993; Griffiths et al., 1995; Westermark et al., 1990). We found, however, that this tetrapeptide alone is not able to aggregate into $\beta$-sheets and amyloid-like fibrils in aqueous solutions, whereas its $\mathrm{N}$-terminal extension by only one residue results in the strongly amyloidogenic hIAPP(23-27) (FGAIL). Nevertheless, (24-27) (GAIL) was also found to have a strong propensity to form ordered structures.

Measurement of the kinetics of amyloid formation is a complicated process due to the large number of different self-associated species and the variability of their physical properties (Harper \& Lansbury, 1997). Therefore, several methods are used, often complementary to each other, to obtain independent information about the kinetics of amyloid formation. We used turbidity measurements at $400 \mathrm{~nm}$ to follow the kinetics of insoluble fibril formation (Ashburn \& Lansbury, 1993; Harper \& Lansbury, 1997; Jarrett et al., 1993; Jarrett \& Lansbury, 1993). It should be noted that turbidity measurements at $400 \mathrm{~nm}$ only allow for the detection of aggregates with diameters larger than the wavelength of the incident light beam. Thus, formation of small size and possibly visibly soluble aggregates may be not detectable, and it has been reported that there are amyloid fibrils that do not exhibit turbidity at $400 \mathrm{~nm}$ (Harper \& Lansbury, 1997; Wood et al., 1996). However, the turbiditybased assays are able to detect formation of insoluble amyloid and, therefore, the results of our turbidity assays refer to kinetics of insoluble amyloid formation (Ashburn \& Lansbury, 1993; Harper \& Lansbury, 1997; Jarrett et al., 1993; Jarrett \& Lansbury, 1993). Furthermore, the aggregation assays presented here were performed under stirring conditions, which has been suggested to possibly generate small fibrils that exhibit turbidity, contrary to fibrils formed in non-stirred solutions (Wood et al., 1996).

Thioflavine $\mathrm{T}$ and CR-amyloid binding-based assays are used for the kinetic follow up of aggregation and amyloid formation (Klunk et al., 1989a,b; LeVine, 1993b; Harper \& Lansbury, 1997; Wood et al., 1996, 1995). The exact structural and conformational features of amyloid-forming peptides responsible for binding to both compounds and the binding-induced spectral shifts are not yet understood, and among other factors depend on fibril morphology (Klunk et al., 1989a,b; Harper \& Lansbury, 1997; Wood et al., 1996). According to one report, hIAPP amyloid fails to induce the typical change in the fluorescence spectrum of thiofla$\operatorname{vin} T$, thus precluding the use of this dye to follow the kinetics of hIAPP amyloid formation (LeVine, 1993a). By contrast, hIAPP amyloid readily binds to CR (Kayed et al., 1999; Lorenzo \& Yankner, 1994). A $\beta$ fibrils that were visibly soluble and did not exhibit turbidity at $405 \mathrm{~nm}$ were shown to bind to CR (Wood et al., 1996). To exclude the possibility that amyloid fibrils that were not detectable by the turbidity assay were already present during the lag-time of our aggregational times, we measured the aggregation kinetics of of hIAPP(2327) and hIAPP(22-27) by both turbidity and CRbinding. Identical aggregation kinetics profiles were obtained for the same aggregation solution by both methods, which confirmed the validity of the results of the turbidity assay.

Amyloid formation processes of all amyloidogenic sequences of hIAPP were found to follow kinetics that were consistent with the nucleationdependent polymerization (Jarrett \& Lansbury, 1993). Kinetic solubilities were in the order hIAPP(23-27) (FGAIL) < hIAPP(22-27) (NFGAIL) $\ll$ hIAPP(20-27) (SNNFGAIL) < hIAPP(20-29) (SNN FGAILSS). The thermodynamic solubilities were in the same order. Thus, the differences in the apparent (kinetic) solubilities between these sequences are due to both kinetic and thermodynamic effects. The large kinetic and thermodynamic solubilities of hIAPP(23-27) (FGAIL) suggested that the high $\beta$-sheet contents of its fibrillar form did not contribute significantly to fibril formation rates and stability, factors that may be closely related to monomer association and the fibril dissociation equilibrium constants. Thus, the $\beta$-sheet content of fibrils of a particular sequence may not necessarily 
reflect its kinetic and thermodynamic solubilities. The observed low kinetic and thermodynamic solubilities of the longer partial hIAPP sequences may be due to additional fibril-stabilizing interactions, i.e. hydrophobic interactions that could play a role in a longer sequence, whereas the high entropic cost of self-association would inhibit such an effect in the short sequences (Jarrett \& Lansbury, 1993; Weinreb et al., 1994).

All fibrillar aggregates were cytotoxic to a pancreatic $\beta$-cell line, whereas the soluble forms of the peptide fragments showed no toxicity. These findings were consistent with the previously described strong toxicity of hIAPP fibrils and the lack of toxicity of soluble hIAPP, and show for the first time that fibrils of hIAPP(20-29) are also cytotoxic (Lorenzo et al., 1994; Lorenzo \& Yankner, 1994; May et al., 1993). Interestingly, the fragments that were studied were about 1000-fold less toxic than fibrillar hIAPP. A possible reason that may account for this finding might be their about 100 to 1000fold higher kinetic and/or thermodynamic solubilities as compared to the highly insoluble hIAPP (Kayed et al., 1999). This would affect both their aggregational lag-time and the stability of their fibrils towards dissociation (Jarrett \& Lansbury, 1993).

Here, we show that penta- and hexapeptide sequences of hIAPP, hIAPP(23-27) (FGAIL) and hIAPP(22-27) (NFGAIL), are sufficient for $\beta$-sheet and cytotoxic amyloid fibril formation. Our studies also suggest that, apart from the $\beta$-sheet structure itself, there are several yet unidentified conformational features that may be involved in the mechanism of peptide self-assembly into fibrils. Our results confirm the dependence of cytotoxicity of an amyloid-forming peptide on its molecular assembly form (Burdick et al., 1992; Iversen et al., 1995; Lorenzo et al., 1994; Lorenzo \& Yankner, 1994; Pike et al., 1991, 1995). Short sequences containing crucial residues for amyloid formation and their analogs have been recently used as $\beta$-sheet breakers and inhibitors of $A \beta$ amyloid formation (Soto et al., 1998). Thus, the synthetic peptide sequences presented here or rationally designed analogs thereof may find therapeutic applications, since they could be used as, or assist in, the development of inhibitors of pancreatic amyloid formation.

\section{Materials and Methods}

\section{Peptide synthesis}

Syntheses were performed by solid-phase synthetic protocols on 4-alkoxybenzyl alcohol resin from Bachem (Heidelberg, Germany) using the 9-fluorenylmethoxycarbonyl (Fmoc) protecting group for protection of the $\mathrm{N}^{\alpha}$ amino group, the tert-butyl group $(\mathrm{tBu})$ for protection of the side-chain of the Ser residue and the trityl group (Trt) for the side-chain of the Asn residue. Couplings were performed by 2-(1H-benzotriazole-1-yl)-1,1,3,3-tetramethyluronium tetrafluoroborate (TBTU) and a threefold excess of protected amino acids (Bachem,
Heidelberg, Germany) and coupling reagent was used. Deprotected peptides were obtained by treatment of the peptide-resin with $95 \%(\mathrm{v} / \mathrm{v})$ trifluoracetic acid (TFA) at room temperature for two hours, followed by TFA evaporation in vacuum at $30^{\circ} \mathrm{C}$. Crude peptides were either dissolved in acetic acid and precipitated by the addition of chilled diethyl ether, the pellets dried in vacuum, redissolved in $10 \%(\mathrm{v} / \mathrm{v})$ acetic acid and lyophilized, or dissolved in $10 \%$ acetic acid, washed with diethyl ether and lyophilized. Peptides were purified by reverse-phase high-pressure liquid chromatography (RP-HPLC) on a Nucleosil 100 C-18 semi-preparative column (Grom, Herrenberg, Germany) (100 $\mathrm{A}$ pore size, $7-\mu \mathrm{m}$ paricle size, $8 \mathrm{~mm} \times 250 \mathrm{~mm}$ ). Flow rate was $2 \mathrm{ml} /$ minute and the linear gradient used was from $10 \%$ to $90 \%$ eluent B in 30 minutes. Eluents used were: A: $10 \%$ acetonitrile $(\mathrm{ACN})$ in water and $0.058 \%$ trifluoracetic acid (TFA); and B: $90 \%$ ACN in water and $0.05 \%$ TFA. Characterization of the HPLC-purified peptides was performed by fast-atom bombardment mass spectroscopy (FAB-MS) or laser desorption mass spectroscopy (LD-MS) and purity was further confirmed by analytical RP-HPLC.

\section{Kinetic aggregation assays}

Stock solutions for the assays with final apparent peptide concentrations of $5 \mathrm{mM}(1.8-5 \mathrm{mg} / \mathrm{ml}$, depending on the sequence) were prepared by dissolving lyophilized forms of the peptides in DMSO at a concentration of $125 \mathrm{mM}$. Following immediate mixing and sonication for three minutes, stock solutions were then diluted into the assay buffer in disposable plastic cuvettes (pathlength $1 \mathrm{~cm}$ ) and at room temperature as follows: $40 \mu \mathrm{l}$ of the peptide stock solution were added to a mixture of $920 \mu \mathrm{l}$ of aqueous $10 \mathrm{mM}$ sodium phosphate buffer ( $\mathrm{pH} 7.4)$, and $40 \mu \mathrm{l}$ of $20 \mathrm{mM}$ sodium phosphate buffer ( $\mathrm{pH}$ 7.4). Immediately thereafter, the solution was stirred by a magnetic stirring bar $(3 \mathrm{~mm} \times 10 \mathrm{~mm})$ and turbidity (absorbance at $400 \mathrm{~nm}$ ) was measured over several time points. Aggregation assays were always performed in duplicate in the same experimental set and experiments were repeated in three independent experimental settings. Buffers were always sterile-filtered $(0.22 \mu \mathrm{m})$ prior to the experiment. Thermodynamic solubilities are the mean $( \pm S E M)$ of three or four independent aggregation experiments, performed as descibed above and were determined four days following the start of the aggregation experiment as follows: peptide suspensions were centrifuged $(12,000 \mathrm{~g})$ for ten minutes, supernatants recovered and remaining soluble peptide quantified by RP-HPLC analysis using various concentrations of the respective peptide as calibration standards. Pellets were dried over $\mathrm{KOH}$ platlets and suspended in water, ${ }^{2} \mathrm{H}_{2} \mathrm{O}$, or cell culture medium at $2.6-5 \mathrm{mg} / \mathrm{ml}$, depending on the sequence (apparent concentration of $5 \mathrm{mM}$ ) to be used for the AFM, FT-IR, and cytotoxicity studies, respectively.

Seeding experiments were performed parallel with aggregation assays of non-seeded solutions and the same stock solutions were used for both assays to exclude possible variations of the lag-time due to different stocks (Harper \& Lansbury, 1997; Kapurniotu et al., 1998; Kayed et al., 1999). Because we wanted to probe the nucleation dependence of aggregation of the hIAPP fragments, it was necessary to identify conditions above the saturation level of the peptide solutions that lead to peptide aggregation after a significant lag-time (Harper \& Lansbury, 1997). Therefore, hIAPP(22-27) (NFGAIL) was applied at $2.4 \mathrm{mg} / \mathrm{ml}$ (apparent concentration of 
$3.75 \mathrm{mM}$ ) which resulted in a significant aggregation lag-time (ten hours). Both, the aggregation and seeding experiments of the $2.4 \mathrm{mg} / \mathrm{ml}$ hIAPP(22-27) solution were performed in $10 \mathrm{mM}$ sodium phosphate buffer (pH 7.4), containing $2 \%$ DMSO and about $0.24 \mathrm{mg} / \mathrm{ml}$ (10\%) preformed hIAPP(22-27) (NFGAIL) fibrils. The seeding experiment of hIAPP(23-27) (FGAIL) was performed at $2.6 \mathrm{mg} / \mathrm{ml}$ peptide (apparent concentration of $5 \mathrm{mM}$ ) with $0.26 \mathrm{mg} / \mathrm{ml}$ (10\%) preformed hIAPP(23-27) fibrils as described above. At this peptide concentration insoluble amyloid formation in an unseeded solution set in after a lag-time of about 32 hours.

The results of several turbidity assays were confirmed by the CR binding assay (Benditt et al., 1970; Klunk et al., 1989a,b) which was performed as follows: at various time points, aliquots $(40 \mu \mathrm{l})$ of solutions used for turbidity measurements were removed and mixed with $40 \mu \mathrm{l}$ of a $25 \mu \mathrm{M}$ CR solution in $10 \mathrm{mM}$ potassium phosphate buffer ( $\mathrm{pH} 7.4$ ), containing $150 \mathrm{mM} \mathrm{NaCl}$, reactions incubated for 30 minutes at room temperature and bound CR determined as described (Benditt et al., 1970; Klunk et al., 1989a; Wood et al., 1996).

\section{FT-IR spectroscopy}

Insoluble aggregates formed after four days in a kinetic aggregation experiment, were collected, quantified, and dried as described above. They were resuspended in ${ }^{2} \mathrm{H}_{2} \mathrm{O}$ at an apparent concentration of $5 \mathrm{mM}$, applied onto a $\mathrm{CaF}_{2}$ plate and air-dried. Spectra were measured in a Perkin-Elmer spectrophotometer (Spectrum 1000). Spectra of non-amyloidogenic peptides were measured after incubation of $10 \mathrm{mM}$ solutions in ${ }^{2} \mathrm{H}_{2} \mathrm{O}$ for four days at room temperature. The aged solutions were then applied onto a $\mathrm{CaF}_{2}$ plate, air-dried, and measured. The same peptide preparations that were used for all other assays were applied also for the FT-IR studies and no additional purification steps of the HPLC-purified peptides were performed to replace potential TFA counterions by cloride. Such TFA-replacing procedures are usually performed to exclude the presence of absorbance bands of TFA in the IR spectrum (Moriarty \& Raleigh, 1999). However, we reasoned that all biophysical and conformational studies on one sequence should be performed with a chemically identical peptide preparation to avoid possible effects of different counterions on the properties of the peptide. In fact, it has often been demonstrated that biophysical, conformational, and also cytotoxic properties of amyloidogenic peptides may vary dramatically depending on the solvents or salts used for their preparation (Kaneko \& Tutumi, 1997; Shen \& Murphy, 1995). Since no basic residues are present in the sequences studied here, our FT-IR studies should reasonably allow for a comparative and qualitative study of the secondary structure differences between the fibrillar forms of the peptides.

\section{Electron microscopy}

Incubations of peptides at $1.8-10 \mathrm{mg} / \mathrm{ml}$ (apparent concentrations of 5 to $10 \mathrm{mM}$ ) were performed in $10 \mathrm{mM}$ sodium phosphate buffer ( $\mathrm{pH} 7.4$ ), for six days at room temperature. Formation of fibrils was assessed after three and six days of incubation as recently described by Kayed et al. (1999) using a Zeiss EM 109 electron microscope operated at $80 \mathrm{kV}$.

\section{Atomic force microscopy (AFM)}

The insoluble aggregates formed in $50 \mu \mathrm{l}$ of a kinetic aggregation experiment (apparent concentration of $5 \mathrm{mM}$ ) were collected and resuspended in $\mathrm{H}_{2} \mathrm{O}$ at a final concentration of $5 \mathrm{mM}$. The non-amyloidogenic peptides hIAPP(24-27) (GAIL) and the rIAPP sequences were dissolved at peptide concentrations of $10 \mathrm{mM}$ in water and aged for four days before AFM examination. Following dilution down to micromolar concentrations, $5 \mu \mathrm{l}$ was placed on a square cover glass $(15 \mathrm{~mm} \times 15 \mathrm{~mm})$ and then air-dried. Images were obtained with an AUTOPROBE CP Microscope (Park Scientific Instruments, Sunnyvale, CA) and the non-contact-mode technique essentially as recently described (Kayed et al., 1999). The scanning parameters applied for the images presented in the Figures were drive amplitude between 8 and $19 \mathrm{~V}$ and scan rate between 1.2 and $1.5 \mathrm{~Hz}$. Diameters of the fibrils and dimensions of the aggregates were determined as recently described (Kayed et al., 1999; Harper et al., 1997b; Stine et al., 1996).

\section{Congo red staining}

A $10 \mu \mathrm{l}$ aliquot of an aged supersaturated peptide suspension or an aged highly concentrated solution (1.8$10 \mathrm{mg} / \mathrm{ml}$, apparent concentrations of $5-10 \mathrm{mM}$ ) in $10 \mathrm{mM}$ sodium phosphate buffer ( $\mathrm{pH} 7.4$ ), four days incubation, or a $10 \mu \mathrm{l}$ aliquot of a kinetic aggregation assay suspension after peptide insolubilization was completed (four days) was allowed to air-dry on a glass microscope slide. Staining was performed by the addition of a solution of $1 \mathrm{mM} \mathrm{CR}$ in $100 \mathrm{mM} \mathrm{NaCl}$ and $10 \mathrm{mM}$ sodium phosphate buffer ( $\mathrm{pH} 7.4$ ), followed by drying of the solution and rinsing with double-distilled water to remove excess CR (Jarrett \& Lansbury, 1992) or by the addition of a saturated CR solution in $80 \%(\mathrm{v} / \mathrm{v})$ ethanol (McLean \& Balasubramaniam, 1992). The former method was applied for peptides hIAPP(22-27) and (2327 ) and the latter for the staining of the highly water-soluble peptide hIAPP(24-27) (done at a peptide concentration of $25 \mathrm{mM}$ ) and the rest of the peptides. Birefringence was determined with an OLYMPUS BH2 light microscope (Olympus, Tokyo, Japan) under polarized light.

\section{In vitro cytotoxicity studies}

The rat insulinoma cell line RIN5fm was obtained by T. E. Rucinsky from the Washington University Tissue Culture Support Center and was cultured in RPMI 1640 containing $10 \%$ heat-inactivated fetal bovine serum, $2 \mathrm{mM}$ L-glutamine, $0.1 \mathrm{mM}$ non-essential amino acids, $1 \mathrm{mg} / \mathrm{ml}$ glucose, $1 \mathrm{mM}$ sodium pyruvate, and $0.1 \mathrm{mg} /$ $\mathrm{ml}$ penicillin/streptomycin. Cells were plated in 96-well plates at a density of $5 \times 10^{5}$ cells $/ \mathrm{ml}(100 \mu \mathrm{l} /$ well $)$. Following incubation for 24 hours $\left(37^{\circ} \mathrm{C}\right.$, humidified atmosphere with $5 \% \mathrm{CO}_{2}$ ), serial dilutions of the suspensions of the peptide fibrils isolated and quantified from the kinetic aggregation experiments as described above or of the freshly dissolved peptides were made in cell culture medium and $11 \mu \mathrm{l}$ added into each well. Incubations were performed for about 20 hours and cell viability was then assessed by measuring the cellular reduction of MTT (Kapurniotu et al., 1998; Shearman et al., 1994). 


\section{Acknowledgments}

We thank M. Duszenko and G. Dußling for assistance with the EM, C. Oehr and T. Mayer for assistance with the AFM measurements, B. Pfeiffer-Guglielmi and B. Hamprecht for help with and use of cell culture facilities and R. Bucala and A. Cerami for helpful discussions. This work was supported by an institutional grant of The Fraunhofer Institute for Interfacial and Biological Engineering (FhIGB, Stuttgart, Germany).

\section{References}

Ashburn, T. T. \& Lansbury, P. T., Jr (1993). Interspecies variations affect the kinetics and thermodynamics of amyloid plaque formation: Peptide models of pancreatic amyloid. J. Am. Chem. Soc. 115, 1101211013.

Ashburn, T. T., Auger, M. \& Lansbury, P. T., Jr (1992). The structural basis of pancreatic amyloid formation: Isotope-edited spectroscopy in the solid state. J. Am. Chem. Soc. 114, 790-791.

Benditt, E. P., Eriksen, N. \& Berglund, C. (1970). Congo red dichroism with dispersed amyloid fibrils, an extrinsic Cotton effect. Proc. Natl Acad. Sci. USA, 66, 1044-1051.

Burdick, D., Soreghan, B., Kwon, M., Kosmoski, J., Knauer, M., Henschen, A., Yates, J., Cotman, C. \& Glabe, C. (1992). Assembly and aggregation properties of synthetic Alzheimer's A4/ $\beta$-amyloid peptide. J. Biol. Chem. 267, 546-554.

Chou, P. Y. \& Fasman, G. D. (1978). Empirical predictions of protein conformation. Annu. Rev. Biochem. 47, 251-276.

Clark, A., Lewis, C. E., Willis, A. C., Cooper, G. J. S., Morris, J. F., Reid, K. B. M. \& Turner, R. C. (1987). Islet amyloid formed from diabetes-associated peptide may be pathogenic in type II diabetes. Lancet, ii, 231-234.

Cooper, G. J. S., Willis, A. C., Clark, A., Turner, R. C., Sim, R. B. \& Reid, K. B. M. (1987). Purification and characterization of a peptide from amyloid-rich pancreases of type 2 diabetic patients. Proc. Natl Acad. Sci. USA, 84, 8628-8632.

Cooper, J. H. (1974). Selective amyloid staining as a function of amyloid composition and structure. Lab. Invest. 31, 232-238.

de Koning, E. J. P., Bodkin, N. L., Hansen, B. C. \& Clark, A. (1993). Diabetes mellitus in Macaca mulatta monkeys is characterized by islet amyloidosis and reduction in $\beta$-cell population. Diabetologia, 36, 378384.

Edwards, B. J. \& Morley, J. E. (1992). Amylin. Life Sci. 51, 1899-1912.

Forloni, G., Angeretti, N., Chiesa, R., Monzani, E., Salmona, M., Bugiani, O. \& Tagliavini, F. (1994). Neurotoxicity of a prion protein fragment. Nature, 362, 543-546.

Fraser, P. E., McLachlan, D. R., Surewicz, W. K., Mizzen, C. A., Snow, A. D., Nguyen, J. T. \& Kirschner, D. A. (1994). Conformation and fibrillogenesis of Alzheimer A $\beta$ peptides with selected substitution of charged residues. J. Mol. Biol. 244, 64-73.

Gasset, M., Baldwin, M. A., Lloyd, D. H., Gabriel, J.-M., Holtzman, D. M., Cohen, F., Fletterick, R. \& Prusiner, S. B. (1992). Predicted $\alpha$-helical regions of the prion protein when synthesized as peptides form amyloid. Proc. Natl Acad. Sci. USA, 89, 1094010944.

Glenner, G. G., Eanes, D. \& Wiley, C. (1988). Amyloid fibrils formed from a segment of the pancreatic islet amyloid protein. Biochem. Biophys. Res. Commun. 155, 608-614.

Goldsbury, C. S., Cooper, G. J. S., Goldie, K. N., Müller, S. A., Saafi, E. L., Gruijters, W. T. M., Misur, M. P., Engel, A., Aebi, U. \& Kistler, J. (1997). Polymorphic fibrillar assembly of human amylin. J. Struct. Biol. 119, 12-27.

Goldsbury, C., Kistler, J., Aebi, U., Arvinte, T. \& Cooper, G. J. S. (1999). Watching amyloid fibrils grow by time-lapse atomic force microscopy. J. Mol. Biol. 285, 33-39.

Griffiths, J. M., Ashburn, T. T., Auger, M., Costa, P., Griffin, R. G. \& Lansbury, P. T., Jr (1995). Rotational resonance solid-state NMR elucidates a structural model of pancreatic amyloid. J. Am. Chem. Soc. 117, 3539-3546.

Harper, J. D. \& Lansbury, P. T., Jr (1997). Models of amyloid seeding in Alzheimer's disease and scrapie: Mechanistic truths and physiological consequences of the time-dependent solubility of amyloid proteins. Annu. Rev. Biochem. 66, 385-407.

Harper, J. D., Lieber, C. M. \& Lansbury, P. T., Jr (1997a). Atomic force microscopic imaging of seeded fibril formation and fibril branching by the Alzheimer's disease amyloid- $\beta$ protein. Chem. Biol. 4, 951-959.

Harper, J. D., Wong, S. S., Lieber, C. M. \& Lansbury, P. T., Jr (1997b). Observation of metastable A $\beta$ amyloid protofibrils by atomic force microscopy. Chem. Biol. 4, 119-125.

Hilbich, C., Kisters-Woike, B., Reed, J., Masters, C. L. \& Beyreuther, K. (1991). Aggregation and secondary structure of synthetic amyloid $\beta$ A4 peptides of Alzheimer's disease. J. Mol. Biol. 218, 149-163.

Inouye, H., Fraser, P. E. \& Kirschner, D. A. (1993). Structure of $\beta$-crystallite assemblies formed by Alzheimer $\beta$-amyloid protein analogues: analysis by X-ray diffraction. Biophys. J. 64, 502-519.

Iversen, L. L., Mortishire-Smith, J., Pollack, S. J. \& Shearman, M. S. (1995). The toxicity in vitro of $\beta$-amyloid protein. Biochem. J. 311, 1-16.

Jarrett, J. T., Berger, E. P. \& Lansbury, P. T., Jr (1993). The carboxy terminus of the $\beta$ amyloid protein is critical for the seeding of amyloid formation: Implications for the pathogenesis of Alzheimer's disease. Biochemistry, 32, 4693-4697.

Jarrett, J. T. \& Lansbury, P. T., Jr (1992). Amyloid fibril formation requires a chemically discriminating nucleation event: Studies of an amyloidogenic sequence from the bacterial protein OsmB. Biochemistry, 31, 12345-12352.

Jarrett, L. L. \& Lansbury, P. T., Jr (1993). Seeding onedimensional crystallization of amyloid: a pathogenic mechanism in Alzheimer's disease and scrapie? Cell, 73, 1055-1058.

Kaneko, I. \& Tutumi, S. (1997). Conformations of $\beta$-amyloid in solution. J. Neurochem. 68, 438-439.

Kapurniotu, A., Bernhagen, J., Greenfield, N., Al-Abed, Y., Teichberg, S., Frank, R. W., Voelter, W. \& Bucala, R. (1998). Contribution of advanced glycosylation to the amyloidogenicity of islet amyloid polypeptide. Eur. J. Biochem. 251, 208-216.

Kayed, R., Bernhagen, J., Greenfield, N., Sweimeh, K., Brunner, H., Voelter, W. \& Kapurniotu, A. (1999). Conformational transitions of islet amyloid poly- 
peptide (IAPP) in amyloid formation in vitro. J. Mol. Biol. 287, 781-796.

Klunk, W. E., Pettegrew, J. W. \& Abraham, D. J. (1989a). Quantitative evaluation of congo red binding to amyloid-like proteins with a beta-pleated sheet conformation. J. Histochem. Cytochem. 37, 1273-1281.

Klunk, W. E., Pettegrew, J. W. \& Abraham, D. J. (1989b). Two simple methods for quantifying lowaffinity dye-substrate binding. J. Histochem. Cytochem. 37, 1293-1297.

Kominos, D. (1995). Towards understanding amyloid aggregation. Biophys. J. 69, 739-740.

Krimm, S. \& Bandekar, J. (1986). Vibrational spectroscopy and conformation of peptides, polypeptides and proteins. Advan. Protein Chem. 38, 181-364.

Lansbury, P. T., Jr (1992). In pursuit of the molecular structure of amyloid plaque: New technology provides unexpected and critical information. Biochemistry, 31, 6865-6870.

Lansbury, P. T., Jr (1996). A reductionist view of Alzheimer's disease. Acc. Chem. Res. 29, 317-321.

LeVine, H., III. (1993a). Thioflavine T forms uniquely fluorescent complexes with amyloid structures of synthetic Alzheimer's disease $\beta$-amyloid peptides and insulin in solution. In Amyloid Amyloidosis 1993, Proc. 7th Int. Symp. Amyloidosis (Kisilevski, R., ed.), pp. 383-385, Parthenon Publications, New York.

LeVine, H., III (1993b). Thioflavine T interaction with synthetic Alzheimer's disease $\beta$-amyloid peptides: detection of amyloid aggregation in solution. Protein Sci. 2, 404-410.

Lorenzo, A. \& Yankner, B. A. (1994). ß-Amyloid neurotoxicity requires fibril formation and is inhibited by congo red. Proc. Natl Acad. Sci. USA, 91, 1224312247.

Lorenzo, A., Razzboni, B., Weir, G. C. \& Yankner, B. A. (1994). Pancreatic islet cell toxicity of amylin associated with type-2 diabetes mellitus. Nature, 368, 756760.

Lundberg, K. M., Stenland, C. J., Cohen, F. E., Prusiner, S. B. \& Millhauser, G. L. (1997). Kinetics and mechanism of amyloid formation by the prion protein $\mathrm{H} 1$ peptide as determined by time-dependent ESR. Chem. Biol. 4, 345-355.

Luskey, K. L. (1992). Possible links between amylin and diabetes. Diabetes Care, 41, 297-299.

Mattson, M. P., Cheng, B., Davis, D., Bryant, K., Lieberburg, I. \& Rydel, R. E. (1992). $\beta$-amyloid peptides destabilize calcium homeostasis and render human cortical neurons vulnerable to excitotoxicity. J. Neurosci. 12, 376-389.

May, P. C., Boggs, L. N. \& Fuson, K. (1993). Neurotoxicity of human amylin to rat primary hippocampal cultures: Similarity to Alzheimer's disease amyloid $\beta$-neurotoxicity. J. Neurochem. 61, 2330-2333.

McLean, L. R. \& Balasubramaniam, A. (1992). Promotion of $\beta$-structure by interaction of diabetes-associated polypeptide (amylin) with phosphatidylcholine. Biochim. Biophys. Acta, 1122, 317-320.

Moriarty, D. F. \& Raleigh, D. P. (1999). Effects of sequential proline substitutions on amyloid for-

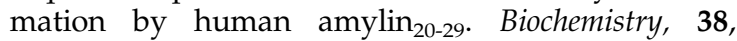
1811-1818.

Nishi, M., Chan, S. J., Nagamatsu, S., Bell, G. I. \& Steiner, D. F. (1989). Conservation of the sequence of islet amyloid polypeptide in five mammals is consistent with its putative role as an islet hormone. Proc. Natl Acad. Sci. USA, 86, 5738-5742.
Pike, C. J., Walencewicz, A. J., Glabe, C. G. \& Cotman, C. W. (1991). In vitro aging of $\beta$-amyloid protein causes peptide aggregation and neurotoxicity. Brain Res. 563, 311-314.

Pike, C. J., Walencewicz-Wasserman, A. J., Kosmoski, J., Cribbs, D. H., Glabe, C. G. \& Cotman, C. W. (1995). Structure-activity analyses of $\beta$-amyloid peptides: contibutions of the $\beta 25-35$ region to aggregation and neurotoxicity. J. Neurochem. 64, 253-265.

Rink, T. J., Beaumont, K., Koda, J. \& Young, A. (1993). Structure and biology of amylin. Trends Pharm. Sci. 14, 113-118.

Schubert, D., Behl, C., Lesley, R., Brack, A., Dargusch, R., Sagara, Y. \& Kimura, H. (1995). Amyloid peptides are toxic via a common oxidative mechanism. Proc. Natl Acad. Sci. USA, 92, 1989-1993.

Shearman, M. S., Hawtin, S. R. \& Tailor, V. J. (1995). The intracellular component of cellular 3-(4,5dimethythiazol-2-yl)-2,5-diphenyltetrazolium bromide (MTT) reduction is specifically inhibited by $\beta$-amyloid peptides. J. Neurochem. 65, 218-227.

Shearman, M. S., Ragan, C. I. \& Iversen, L. L. (1994). Inhibition of PC12 cell redox activity is a specific, early indicator of the mechanism of $\beta$-amyloidmediated cell death. Proc. Natl Acad. Sci. USA, 91, 1470-1474.

Shen, C.-L. \& Murphy, R. M. (1995). Solvent effects on self-assembly of $\beta$-amyloid peptide. Biophys. J. 69, 640-651.

Sipe, J. D. (1994). Amyloidosis. Crit. Rev. Clin. Lab. Sci. 31, 325-354.

Soto, C. \& Frangione, B. (1995). Two conformational states of amyloid $\beta$-peptide: implications for the pathogenesis of Alzheimer's disease. Neurosci. Letters, 186, 115-118.

Soto, C., Sigurdsson, E. M., Morelli, L., Kumar, R. A., Castano, E. M. \& Frangione, B. (1998). $\beta$-sheet breaker peptides inhibit fibrillogenesis in rat brain model of amyloidosis: implications for Alzheimer's therapy. Nature Med. 4, 822-826.

Stine, W. B., Jr., Snyder, S. W., Ladror, U. S., Wade, W. S., Miller, M. F., Perun, T. J., Holzman, T. F. \& Krafft, G. A. (1996). The nanometer-scale structure of amyloid- $\beta$ visualized by atomic force microscopy. J. Protein Chem. 15, 193-202.

Thomas, P. J., Qu, B.-H. \& Pedersen, P. L. (1995). Defective protein folding as a basis of human disease. Trends Biochem. Sci. 20, 456-459.

Tjernberg, L. O., Callaway, D. J. E., Tjernberg, A., Hahne, S., Lilliehöök, C., Terenius, L., Thyberg, J. \& Nordstedt, C. (1999). A molecular model of Alzheimer amyloid $\beta$-peptide fibril formation. J. Biol. Chem. 274, 12619-12625.

Weinreb, P. H., Jarrett, J. T. \& Lansbury, P. T., Jr (1994). Peptide models of a hydrophobic cluster at the C-terminus of the $\beta$-amyloid protein. J. Am. Chem. Soc. 116, 10835-10836.

Westermark, P., Engström, U., Johnson, K., Westermark, G. T. \& Betsholz, C. (1990). Islet amyloid polypeptide: pinpointing amino acid residues linked to amyloid fibril formation. Proc. Natl Acad. Sci. USA, 87, 5036-5040.

Westermark, P., Wernstedt, C., Wilander, E., Hayden, D. W., O'Brien, T. D. \& Johnson, K. H. (1987). Amyloid fibrils in human insulinoma and islet of Langerhans of the diabetic cat are derived from a neuropeptide-like protein also present in normal islet cells. Proc. Natl Acad. Sci. USA, 84, 3881-3885. 
Wood, S. J., Maleeff, B., Hart, T. \& Wetzel, R. (1996). Physical, morphological and functional differences between $\mathrm{pH} 5.8$ and 7.4 aggregates of the Alzheimer's amyloid peptide A $\beta$. J. Mol. Biol. 256, 870-877.

Wood, S. J., Wetzel, R., Martin, J. D. \& Hurle, M. R. (1995). Prolines and amyloidogenicity in fragments of the Alzheimer's peptide $\beta /$ A4. Biochemistry, 34, 724-730.

Zhang, S. \& Rich, A. (1997). Direct conversion of an oligopeptide from a $\beta$-sheet to an $\alpha$-helix: a model for amyloid formation. Proc. Natl Acad. Sci. USA, 94, 23-28.

Edited by R. Huber

(Received 14 September 1999; received in revised form 24 November 1999; accepted 24 November 1999) 